\title{
Recent Advancements in the Regeneration of Auditory Hair Cells and Hearing Restoration
}

\author{
Rahul Mittal ${ }^{1}$, Desiree Nguyen ${ }^{1}$, Amit P. Patel ${ }^{1}$, Luca H. Debs ${ }^{1}$, Jeenu Mittal ${ }^{1}$, \\ Denise Yan ${ }^{1}$, Adrien A. Eshraghi ${ }^{1}$, Thomas R. Van De Water ${ }^{1}$ and Xue Z. Liu ${ }^{1,2 *}$ \\ ${ }^{1}$ Department of Otolaryngology, University of Miami Miller School of Medicine, Miami, FL, United States, ${ }^{2}$ Department \\ of Otolaryngology, Xiangya Hospital, Central South University, Changsha, China
}

Neurosensory responses of hearing and balance are mediated by receptors in specialized neuroepithelial sensory cells. Any disruption of the biochemical and molecular pathways that facilitate these responses can result in severe deficits, including hearing loss and vestibular dysfunction. Hearing is affected by both environmental and genetic factors, with impairment of auditory function being the most common neurosensory disorder affecting 1 in 500 newborns, as well as having an impact on the majority of elderly population. Damage to auditory sensory cells is not reversible, and if sufficient damage and cell death have taken place, the resultant deficit may lead to permanent deafness. Cochlear implants are considered to be one of the most successful and consistent treatments for deaf patients, but only offer limited recovery at

OPEN ACCESS

Edited by: Detlev Boison, Legacy Health, United States

Reviewed by: Munjal M. Acharya, University of California, Irvine School of Medicine, United States Allison B. Coffin, Washington State University, United States Philip Forsyth Copenhaver, Oregon Health and Science University, United States

*Correspondence: Xue Z. Liu xliu@med.miami.edu

Received: 12 April 2017 Accepted: 11 July 2017 Published: 31 July 2017

Citation:

Mittal R, Nguyen D, Patel AP, Debs LH, Mittal J, Yan D, Eshraghi AA, Van De Water TR and Liu XZ (2017) Recent Advancements in the Regeneration of Auditory Hair Cells and Hearing Restoration.

Front. Mol. Neurosci. 10:236. doi: 10.3389/fnmol.2017.00236 the expense of loss of residual hearing. Recently there has been an increased interest in the auditory research community to explore the regeneration of mammalian auditory hair cells and restoration of their function. In this review article, we examine a variety of recent therapies, including genetic, stem cell and molecular therapies as well as discussing progress being made in genome editing strategies as applied to the restoration of hearing function.

\section{Keywords: auditory hair cells, hair cell regeneration, hearing loss, gene therapy, stem cell therapy}

\section{INTRODUCTION}

Hearing loss is a serious global morbidity that affects 360 million people worldwide (WHO, 2013). Hearing loss is a neurological disability that impacts both the physical and mental well-being of patients (Contrera et al., 2016; Roland et al., 2016; Goman et al., 2017; Homans et al., 2017). At the basic level, loss of hearing is a source of isolation and depression for patients due to the importance of hearing in communication (Li et al., 2014; Sun et al., 2016; Tseng et al., 2016). Individuals with hearing disabilities often have to rely more heavily on caretakers. Patients with hearing loss are at increased risk for accidental injury due to their loss of this sense (Smith, 2015). Children with hearing loss are at danger of diminished neurological cognitive development as a result of their reduced exposure to sound stimuli and language (Boulet et al., 2009; Stevenson et al., 2015; Niclasen et al., 2016; Roland et al., 2016). Hearing loss represents a profound burden for both patients and the medical system (WHO, 2013; Olusanya et al., 2014).

Hearing loss displays a distribution that correlates with geographic location and socioeconomic trends (Helvik et al., 2009; Emmett and Francis, 2015; Qing et al., 2015; Yan et al., 2015, 2016, 2017). Geographically, hearing loss is most common in Sub-Saharan Africa, the Asia Pacific, and 
Southern Asia (Yan et al., 2015). Socioeconomic status is inversely correlated with hearing loss. The children from low gross national income (GNI) nations display a $2 \%$ greater prevalence of hearing loss compared to the incidence of hearing loss in children from high-income groups (Helvik et al., 2009; $\mathrm{WHO}, 2013)$. Adults from low-income nations were found to have a $48 \%$ prevalence of hearing loss, compared to high income groups which displayed a $34 \%$ prevalence of hearing loss (WHO, 2013). A clear correlation between hearing loss and age has also been demonstrated. The incidence of hearing loss at birth is only $0.1 \%$, while approximate $1 / 3$ of all individuals over 65 experience hearing loss (WHO, 2013; Olusanya et al., 2014). The high global prevalence of disabling hearing loss presents an area in clear need for the development of new effective treatments ( $\mathrm{WHO}$, 2013).

The complexity of the auditory system is what makes hearing particularly vulnerable to damage (Moser and Starr, 2016; Mittal et al., 2017). Sound transduction begins at the pinna, which is responsible for the collection and funneling of sound-waves into the auditory canal (Yan and Liu, 2008). At the end of the external auditory canal, sound actuates the tympanic membrane. The tympanic membrane is connected to the bones of the middle ear and travels from malleus to incus to stapes (Figure 1A). The stapes are attached to a membrane on the cochlea known as the oval window. Within the cochlea, the endolymph filled scala media is the vital element of hearing (Figure 1A). Within the scala media, the organ of Corti converts the mechanical energy of sound waves into electrical signals that are transduced to the auditory pathway in the brain (Kazmierczak and Muller, 2012). It does so through the use of hair cells, which contain stereocilia that move in response to specific soundwave initiated fluid waves (Goutman et al., 2015; Figure 1B). Tip links on the stereocilia open ion channels as a result of their movement, allowing for the production of an action potential from the potassium-rich endolymph entering the stereocilia (Karavitaki and Corey, 2010; Verpy et al., 2011). In addition to the essential elements of the conduction pathway, the tensor tympani and the stapedius muscle are responsible for damping the movement of the middle ear bones in response to high levels of sound. The contraction of these muscles is vital for preventing mechanical damage and stimulus-induced hearing loss. Failure in any of the elements of the hearing pathway, including the tensor tympani and stapedius muscles, may result in hearing loss (Yan and Liu, 2008; Géléoc and Holt, 2014; Moser and Starr, 2016; Mittal et al., 2017).

Hearing loss arises from a diverse array of etiologies, including over stimulation of sensory hair cells, trauma to the head, nerve impingement, ototoxic drugs, autoimmune disease and gene mutations (Mijovic et al., 2013; Furness, 2015; Goodall and Siddiq, 2015; Mittal et al., 2015, 2016; Venkatesh et al., 2015; Ben Said et al., 2016; van As et al., 2016). The goal of this review article is to summarize the recent advancements in restoring the hearing function employing new technologies (Table 1). We will also discuss the progress of genome editing technologies, including CRISPR/Cas9, as it might be applied to restore hearing by correcting the deleterious effect of gene mutations and for the restoration of normal physiological function.

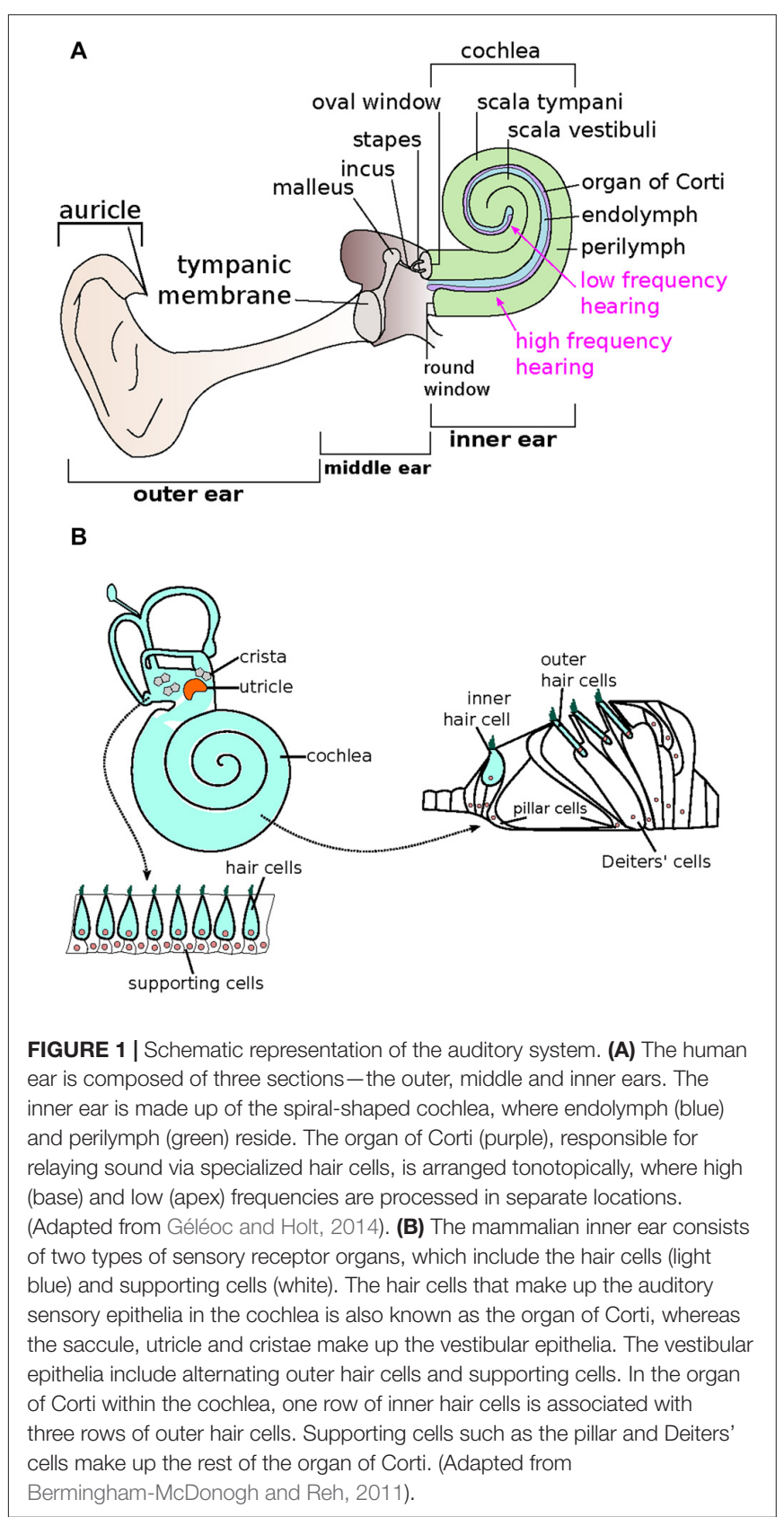

\section{SPECIALIZED SENSORY CELL REGENERATION}

Many modern approaches to hearing restoration focus on the regeneration of the specialized inner ear sensory neuroepithelial cells found on the basilar membrane of the organ of Corti (Basch et al., 2016). The organ of Corti is a complex epithelial structure that utilizes hair cells to produce the action potentials that relay encoded sound to the auditory nerve and then to the central auditory pathway (Goutman et al., 2015). Development of this sensory epithelium involves the differentiation of cells from the cochlear epithelium into stromal cells and parenchymal sensory cells (Barr-Gillespie, 2015; Basch et al., 2016). The 


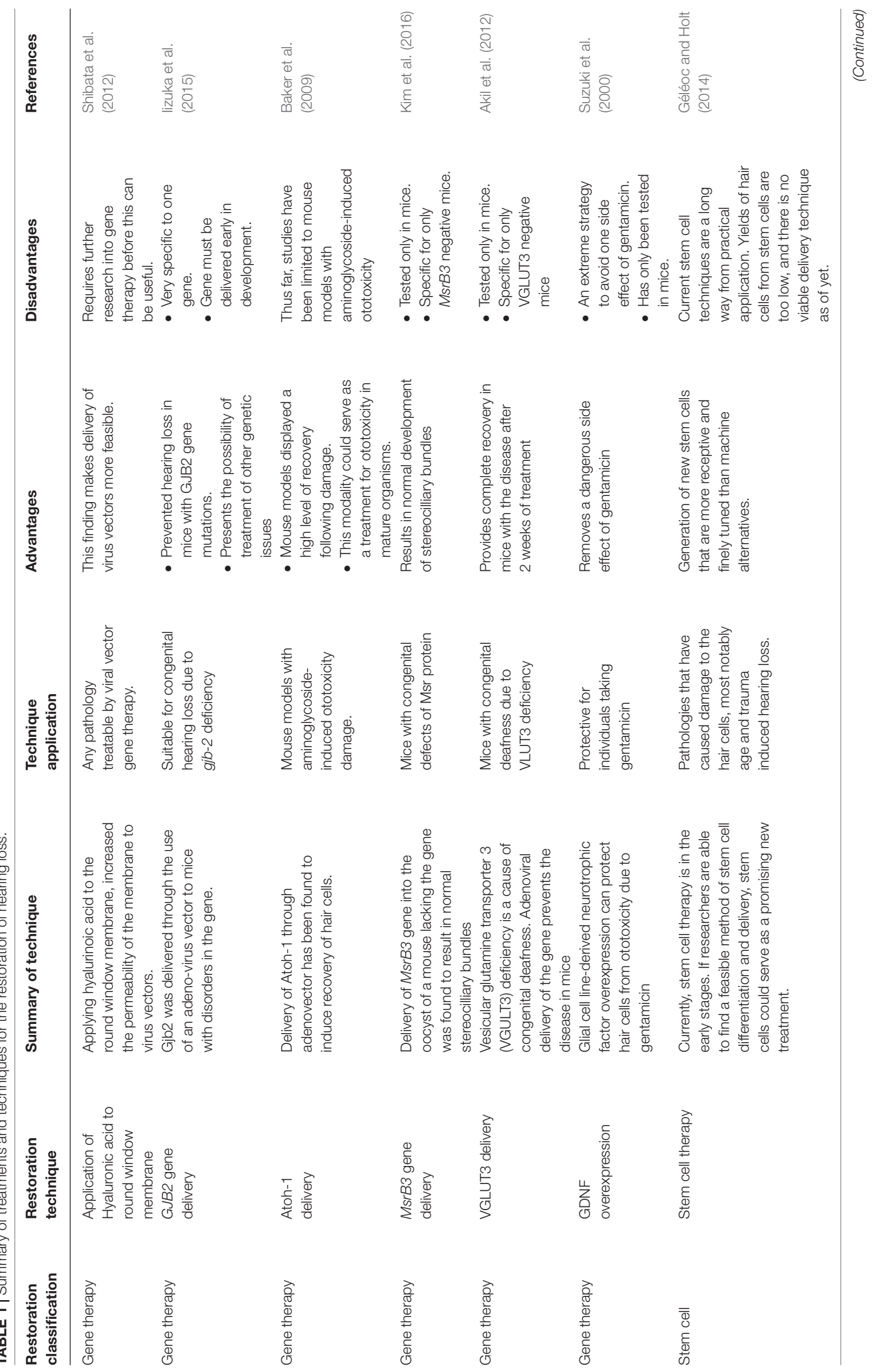




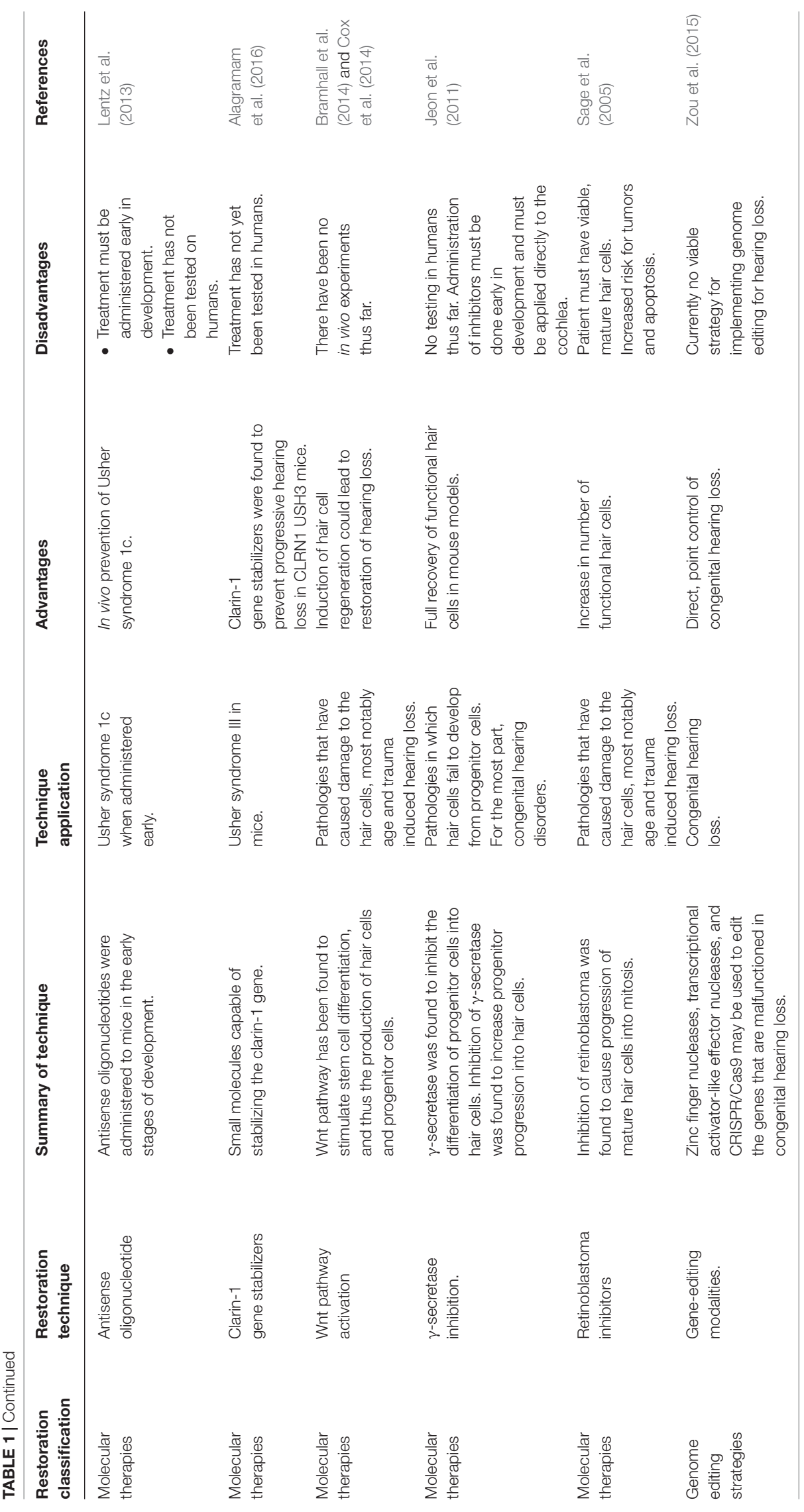


supporting cells are vital for the regulation of the specialized sensory cells, and there is evidence that some of these supporting cells may become specialized sensory cells when exposed to the right sequence of chemical signaling (Géléoc and Holt, 2014; Sienknecht, 2015; Whitfield, 2015). Notch and Wnt signaling are the two predominant pathways that play a crucial role in hair cell differentiation (Mizutari et al., 2013; Li et al., 2015). These two pathways determine the fate which cells will differentiate into hair cells, supporting cells or neurons in the cochlea (Żak et al., 2015; Waqas et al., 2016). Therefore, these two pathways have been targeted to develop hair cell regeneration therapies. Studies of hair cell regeneration center on three approaches: (1) generation of hair cells from intrinsic stem cells; (2) generation of hair cells from existing cochlear supporting cells; and (3) induction of cellular replication followed by maturation of both hair cells and support cells (Géléoc and Holt, 2014).

Stem cell differentiation is currently an immensely popular field of study for hearing restoration, but only moderate results have been achieved with this approach ( $\mathrm{Hu}$ and Ulfendahl, 2013; Géléoc and Holt, 2014). Two issues arise from a stem cell-based regeneration approach. The first is that experiments thus far have produced hair cell like cells, but it is unclear if they have actually produced hair cells. Hair cell like cells differ from normal hair cells as they are generated using stem cells, in vitro. Although these hair cell like cells express markers expressed by normal hair cells, the functionality of these hair cell like cells has yet to be determined. One exception to this has been leucine-rich repeat-containing G-protein coupled receptor 5 (LGR5)-positive cells, which have been found to grow into fully functional hair cells. The finding that LGR5 positive cells were capable of differentiating into hair cells was an important one, but initial studies found that the differentiated cells were low in number, and died quickly after their initial differentiation and maturation (Shi et al., 2012; Bramhall et al., 2014; Cox et al., 2014). This initial finding led to a number of studies that sought to create hair cells with greater success. Control of the Notch and Wnt pathways were found to be effective for this goal. The inhibition of Notch signaling (and thus activation of the Wnt pathway) through the use of small molecule inhibitors resulted in differentiation of LGR5 positive cells into hair cells (Bramhall et al., 2014). Another study demonstrated that inhibition of Notch could induce differentiation of stem cells into hair cells even without the activation of the Wnt pathway (Li et al., 2015). $\beta$-catenin, another Wnt activator, was also found to generate hair cells in vivo, as was the hair cell fate determination factor Atoh1 (Kuo et al., 2015). Further investigations into the field of stem cell differentiation may yield more clinically applicable therapeutics. Mouse models with fluorescence ubiquitination cell cycle indicator (FUCCI) markers (Zielke and Edgar, 2015; Koh et al., 2017) and Lgr5-GFP positive cells (Bramhall et al., 2014), have been used to find small molecules capable of inducing stem cell differentiation into hair cell progenitors. Through the use of these models, a small molecule CHIR99021, a GSK inhibitor capable of inducing cochlear progenitor cells has been identified (Roccio et al., 2015). This finding presents the possibility of a valuable assay for harnessing the potential of stem cells for the design of treatment modalities for hearing loss.

A study attempted one of the most promising breakthroughs into the quantitative limitation of stem cell differentiation to create inner ear sensory epithelia through inducing step-wise differentiation in mouse embryonic stem cells (Koehler et al., 2013). By maintaining tight temporal regulation of bone morphogenetic protein (BMP), transforming growth factor-beta (TGF $\beta$ ), and fibroblast growth factor (FGF), it was possible to generate otic placode-like epithelia that could differentiate into a sensory epithelium with cells possessing stereocilia bundles and kinocilia. The yield was approximately 1500 vestibular-like hair cells/aggregate. These differentiated cells displayed mechanoreceptive capacities and to be capable of synapsing with sensory neurons that were also created within the embryonic stem cell cultures. This development was accomplished by activating BMP while inactivating TGF $\beta$ to induce non-neural ectoderm, then inhibiting BMP and activating FGF to allow for induction of a pre-placodal epithelium (Koehler et al., 2013).

Development of hair cells from cochlear supporting cells is the most promising method of hair cell regeneration. An in vitro study demonstrated that cell cycle manipulation through the use of pharmacologic agents allows for the generation of hair cells from supporting cells. By generating P2 $7^{\text {kip1 }}$ (a cell cycle inhibitor) producing cells, it was possible to induce the production of a small number of hair cells from supporting cells (White et al., 2006). More exciting is the discovery that supporting cells can readily be transformed into hair cells with the use of $\gamma$-secretase (Mizutari et al., 2013). Although this study found shortcomings, such as the need to directly inject $\gamma$-secretase into the inner ear, the fact that this was an in vivo study that restored hearing in mice shows the promise of this approach for hearing restoration in humans.

The induction of mitosis in mature hair cells is currently the least regarded option. The only pathway of manipulation found thus far is the retinoblastoma pathway (Sage et al., 2005). Retinoblastoma protein was found to inhibit progression of mature hair cells into the cell cycle. Inhibition of retinoblastoma was found to induce the production of functional hair cells through mitosis (Mantela et al., 2005; Chen, 2006; Yu et al., 2010). A recent study described the generation of a dominant-negative (DN) retinoblastoma transgenic mouse model (Tarang et al., 2015). The characterization of this mouse model revealed downregulation of retinoblastoma in a number of systems including inner ear. Supernumerary inner HCs (IHCs) were demonstrable in P10 and P28 cochlea especially in the middle and basal turns of the cochlea. However, the manipulation of the retinoblastoma pathway presents the risk of tumors and apoptosis, and further studies are warranted to determine its applicability in hair cell regeneration.

Kremen1, a single pass transmembrane protein, is believed to influence hair cell fate specification (Nakamura et al., 2008). Kremen1 is a receptor protein for dickkopf (DKK), which act as antagonists to the WNT signaling pathway. DKK family proteins binds to Kremen 1 as part of the WNT inhibitory 
complex, resulting in the blockage of WNT signaling and the ultimate $\beta$-catenin degradation (Nakamura et al., 2008). A recent study evaluated different expression pattern effects of Kremen 1 in the prosensory domain of a developing mouse cochlea as well as in the zebrafish lateral line. Using gain- and loss-of-function mutations, it was found that over expression of Kremen 1 drastically inhibited the development of hair cells, and restricted the affected cells to develop into supporting cells. Similarly, decreased levels of Kremen 1 resulted in affected cells to take on a hair cell fate, presumably through canonical Wnt signaling that is required for hair cell formation (Mulvaney et al., 2016). Further studies will help in further deciphering the role of Kremen1 in hair cell regeneration and developing novel treatment modalities.

\section{MOLECULAR APPROACHES TO TREATMENT OF HEARING LOSS AND USHER SYNDROME}

While there are currently no molecular treatments available for hearing loss, molecular approaches have revealed a wealth of information that pertains to hearing loss. The most promising findings have been centered on the treatment of the rare genetic disease, Usher's syndrome. Usher syndrome is the world's most prominent cause of deaf-blindness (Friedman et al., 2011; Bonnet and El-Amraoui, 2012; El-Amraoui and Petit, 2014; Mathur and Yang, 2015; Hartel et al., 2017). The blindness that results from the disease is a form of retinitis pigmentosa, while the deafness is variable depending on the involved genes (Sun et al., 2016). There are three classifications of Usher syndrome, each one resulting from mutations affecting a unique set of genes (Yan and Liu, 2010). Usher syndrome I deafness starts from birth and is the result of defects in genes that regulate the development of stereocilia. These genes include CDH23, USH1C, USH1G, MYO7A and PCDH15 (Bork et al., 2001; Ahmed et al., 2003; Yan and Liu, 2010; Ben-Rebeh et al., 2016). In Usher syndrome II patients, there is difficulty in hearing rather than deafness, and is the result of mutations in DFNB31, GPR98 and USH2A (Ahmed et al., 2003; Yan and Liu, 2010). Usher syndrome III is characterized by progressive hearing loss associated with mutations in CLRN1 that encodes clarin-1 protein (Ahmed et al., 2003; Yan and Liu, 2010; Gopal et al., 2015; Alagramam et al., 2016).

A recent study investigated the potential of treating a mouse model of Usher syndrome with antisense oligonucleotides (ASO; Lentz et al., 2013). In these models, harmonin was found to be truncated. By using specially-designed ASO to replace the mutated c.216G $>$ A nucleic acid in the USH1C gene via the correction of damaged pre-MRNA splicing of transcripts, it was possible to prevent hearing loss in these mice (Lentz et al., 2013). Administration of one ASO dosage minimized Usch1c c.216G $>$ A splicing, improved the organizational structure of cochlear sensory epithelial cells, and improved damaged hair and vestibular cells while improving low-frequency hearing in in vivo mouse models (Lentz et al., 2013). This finding was seen to be useful in the prevention of Usher syndrome 1c when administered in the early stages of development, but not the reversal of the syndrome (Lentz et al., 2013). In another study, the development of Usher syndrome III in mice was prevented by stabilizing the gene for clarin-1 through the use of small molecule, BF844 (Alagramam et al., 2016). The only mutation site known in Usher syndrome III is the gene coding for clarin-1. High throughput screening has been utilized to identify small molecules that could be used to stabilize the CLRN1 ${ }^{\mathrm{N} 48 \mathrm{~K}}$ gene. BF844 was found to stabilize the $C L R N 1^{\mathrm{N} 48 \mathrm{~K}}$ gene, and as such, was seen to prevent the degradation of hearing that is associated with Usher syndrome III. CLRN1 ${ }^{\mathrm{N} 48 \mathrm{~K}}$ USH3 mouse models displayed an increase in hearing of three orders of magnitude when treated with the BF844 molecule, and this treatment was seen to prevent hearing loss when applied before the onset of loss and at the early stages of deafness (Alagramam et al., 2016).

Outside of the treatment of Usher syndrome, molecular studies have mostly been useful only in uncovering information about the generation of hair cells in vitro. Physiological conditions do not allow for the regeneration of hair cells, but it is hypothesized that pharmaceutical agents that target certain genes may result in a regeneration of hair cells. In vitro studies of cochlear supporting cells found that induction of the cell cycle through the use of pharmaceuticals may work to induce the regeneration of hair cells. The manipulation of the Wnt signaling pathway can result in the differentiation of endogenous stem cells into inner ear sensory epithelial cells (Bramhall et al., 2014; Cox et al., 2014). A similar effect has been observed with $\gamma$-secretase, where inhibition led to increased differentiation of progenitor cells into hair cells (Jeon et al., 2011). Understanding the host-signaling pathway that drives the differentiation of hair cells has the potential to provide novel avenues of treatment for hearing loss.

Deafness associated with the loss of sensory hair cells results in progressive pathophysiological changes leading to the degeneration of most auditory neurons (Moser and Starr, 2016). It is now possible to consider these events in the broader context of anti-apoptotic survival factors in the peripheral and central nervous systems. When a neuron is de-afferenated, a loss of neurotrophin proteins changes the oxidative state of biological molecules and leads to the creation of free radicals. The formation of free radicals then alters intracellular levels of $\mathrm{Ca}^{2+}$, increasing expression levels of pro-apoptotic genes (Miller et al., 2002). This degeneration can be prevented by applying chronic electrical stimulation (Miller et al., 2002). The administration of the potent neurotoxin tetrodotoxin in vivo can prevent the effects of electrical stimulation, which shows that $\mathrm{Ca}^{2+}$ mediated action potentials are an integral part of the rescue process. The effects of electrical stimulation can also be blocked by Verapamil, a calcium channel blocker, indicating the need of L-type calcium channel activation for stimulus-driven survival of auditory neurons (Miller et al., 2002). Administration of electrical stimulation can be delayed and can still be of benefit to auditory nerve neurons, even after the start of neuronal apoptosis. Other studies have also 
demonstrated that neurotrophic factor intervention restores auditory function as well as preserves nerve survival and electrophysiological responsiveness in experimental animal models of hearing loss (Shinohara et al., 2002; Yamagata et al., 2004; Sly et al., 2012; Leake et al., 2013). The "neurotrophic factor hypothesis" which is used to explain the effects of aging and neurodegeneration by contending developing neurons compete for limited neurotrophic factor supplies can thus be supported by these studies (Miller et al., 2002; Khalin et al., 2015). With the advancement of new technologies including gene therapy, it will be possible to efficiently deliver the neurotrophic factors into the inner ear to prevent hearing loss.

\section{GENE THERAPY}

Hearing loss can be caused by both environmental and genetic etiological factors, with the genetic contribution comprising for the majority of the cases (Yan and Liu, 2008; Mittal et al., 2015, 2016; Bolz, 2016; Xia W. et al., 2016). To develop therapies for hearing loss due to genetic etiology, methods for gene transfer into the inner ear by in vivo electroporation have been developed (Wang et al., 2012). In a study, E11.5 otocyst were transfected with a plasmid encoding enhanced green fluorescent protein (EGFP). Whole mount immunostaining of the cochlea from a postnatal day 6 (P6) pup whose otocyst was injected and electroporated at E11.5 demonstrated EGFP expression from the base through the middle turn of the cochlea showing efficient gene transfer.

For many ethnic populations, the most prevalent form of genetic deafness is caused by recessive mutations in the gene for a gap junction protein, i.e., beta 2, $26 \mathrm{kDa}$ (GJB2), which is also known as connexin 26 (Cx26; Banjara et al., 2016; Du et al., 2016; Mielczarek et al., 2016; Moctar et al., 2016; Xia H. et al., 2016). A gene delivery system has been used to rescue hearing in a mouse model of GJB2 deletion (Iizuka et al., 2015). Following GJB2 gene deletion, gene delivery systems have been used to replace mutations and improve hearing function in mouse models (Iizuka et al., 2015). A mutation of the $\mathrm{Cx} 26$ (GJB2) gene in mice results in the improper development of cochlear sensory epithelial cells and profound sensorineural deafness. An Adeno-associated viral (AAV) vector can be used to replace a mutated Cx26 with a normal copy of the gene in order to improve hearing function and cochlear development. The use of viral vectors and other methods to replace $\mathrm{Cx} 26$ genes and improve hearing function in mouse models could thus result in the creation of a new gene-based therapies to treat hearing loss due to genetic etiology (Iizuka et al., 2015; Figure 2).

In order to repair lost function to damaged inner ear neuroepithelium, several therapeutic strategies have been suggested (Gubbels et al., 2008; Brigande et al., 2009; Jiang et al., 2013; Depreux et al., 2016; Gomes et al., 2016). Hair cells damaged from vestibular aminoglycoside ototoxicity in mouse models were regenerated using an adeno-vector delivery system to promote genes that express Atoh1 (Baker et al., 2009). Additionally, mice that received the Atoh1 gene therapy showed an improvement in their vestibular function. A number of other studies have demonstrated that administration of Atoh1 gene therapy to the cochlea of embryonic animals (Woods et al., 2004; Gubbels et al., 2008), neonatal animals (Shou et al., 2003; Chen et al., 2013) and mature animals (Izumikawa et al., 2005; Yang et al., 2012; Atkinson et al., 2014) lead to hair cell regeneration though at varying degrees. Although very few treatment options exist for the management of vestibular disorders, hair cell regeneration may serve as a platform to improve these conditions. Development of Atoh1-based gene therapy for vestibular hair cell loss may provide an initial opportunity for developing gene therapy for inner ear diseases.

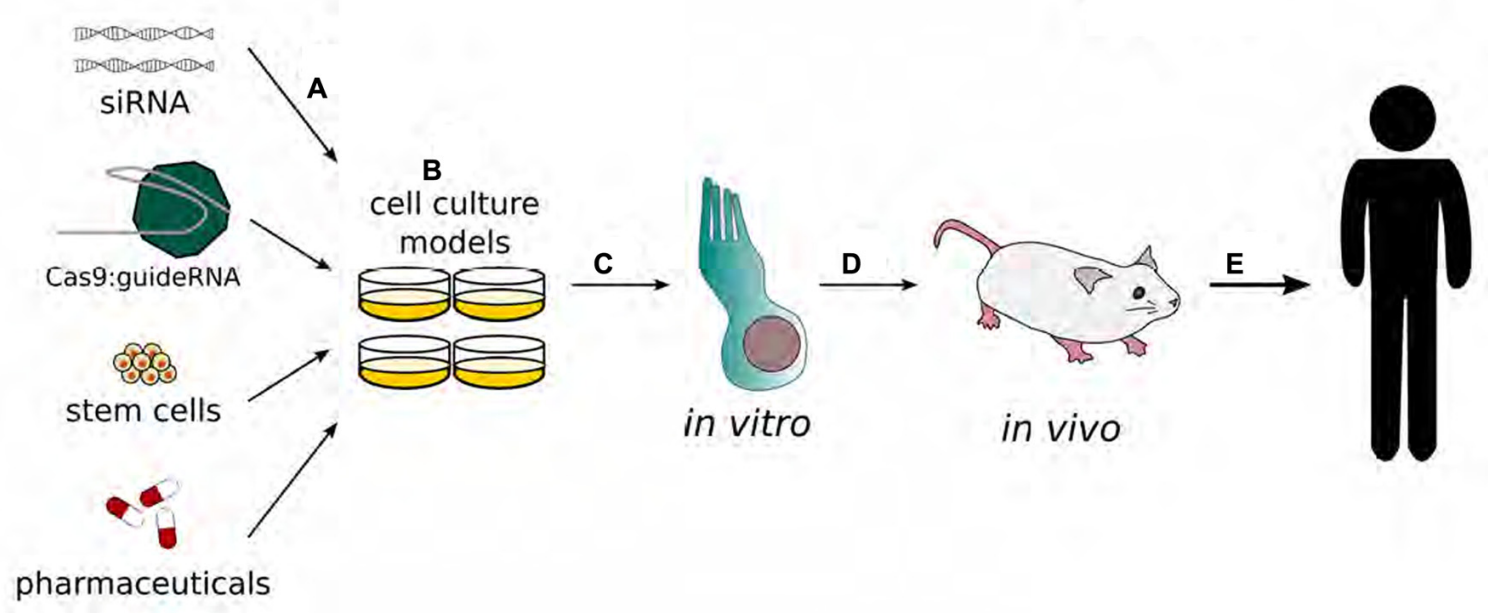

FIGURE 2 | Schematic representation of the development of gene therapy in the inner ear. Gene therapy begins with transfection of adenovirus vectors (A) or drug applications (B) to cell cultures. Modified functions are evaluated in in vitro models, specifically inner and/or outer hair cells. (C) The results with the best outcomes will move on to be tested in in vivo systems (D) to validate therapeutic benefits before being tested in human clinical trials (E). (Adapted from Rousset et al., 2015). 


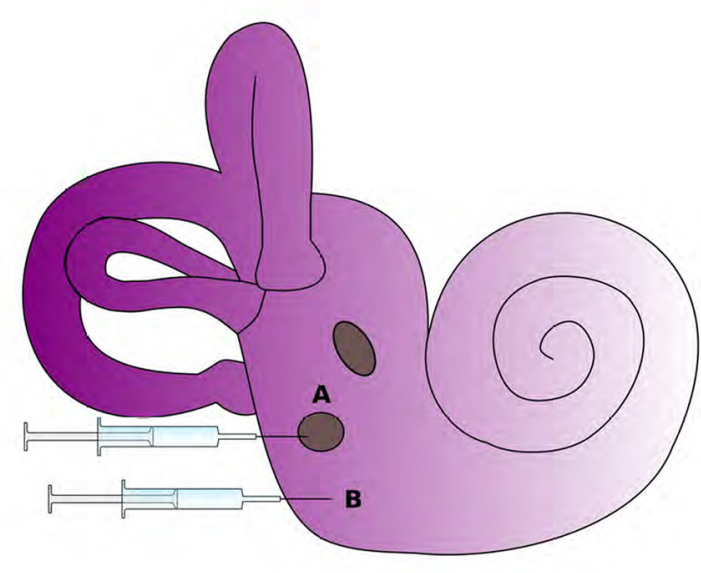

FIGURE 3 | Potential routes for delivery of therapeutics to the inner ear. The round window membrane $(\mathbf{A})$ is accessible from the middle ear space or delivery via cochleostomy (B) is also possible as it directly accesses to inner ear tissues. (Adapted from Rousset et al., 2015).

Cochlear gene therapy might provide a new avenue for the treatment of severe hearing loss by inducing regeneration or phenotypic rescue. One necessary step to establish this therapy is the development of a safe and feasible method and site of delivery of this type of therapy, ideally without requiring drilling the bony wall of the cochlea (Figure 3). Viral vectors are generally impermeable to the round window membrane (RWM) and are unable to cross into the scala tympani perilymph and cochlear epithelial cells. Hyaluronic acid (HA), a nontoxic and biodegradable reagent, has been used to increase RWM permeability to viral vectors in guinea pig models. HA is applied to RWMs in guinea pig models in order to increase inner ear permeability before adeno-viruses deliver an eGFP reporter gene (Ad-eGFP) to cochlear tissues (Shibata et al., 2012). The introduction of transgenes to repair damaged cochlear hair cells is made more feasible by increasing the permeability of the RWM to viral vectors through the usage of HA. The usage of HA is therefore an atraumatic therapy that can potentially improve research methods and future clinical applications (Shibata et al., 2012).

Another important protein associated with hearing in mammals is methionine sulfoxide reductase B3 (MsrB3). MsrB3 stereo-specifically repairs methionine-R-sulfoxide, which is an altered protein created by reactive oxygen species that can lead to inner ear tissue damage (Ahmed et al., 2011; Kwon et al., 2014). A down-regulation of MsrB3 gene was found to cause severe to profound congenital hearing loss due to the damage of inner ear sensory epithelia. Down-regulation of $M s r B 3$ leads to a disorganization of inner ear cells, leading to epithelial cell damage and ultimate cellular apoptosis (Shen et al., 2015). In mice models, MsrB3 gene can be delivered to developing embryos using transgene therapy. Through the use of a transuterine delivery method, an adenovirus vector can deliver $M s r B 3$ gene around embryonic day 12.5 into MsrB3 (-/-) mouse otocyst. Treated mice have demonstrated hearing recovery on postnatal day 28, and MsrB3 mRNA as well as protein expression was demonstrable in the cochlear extracts. Additionally, the morphology of the stereociliary bundles in the rescued ears of MsrB3(-/-) mice were similar to those in normal MsrB3(+/+) animals (Kim et al., 2016).

Glutamate receptors are involved in the hearing function (Seal and Edwards, 2006; Obholzer et al., 2008; Lee et al., 2015; Münster-Wandowski et al., 2016). Congenital deafness is also observed in mice models that lack a vesicular glutamate transporter-3 (VGLUT3). This hearing loss is a result of a decrease in glutamate release at the inner hair cell afferent synapse (Ruel et al., 2008; Seal et al., 2008). When using an adeno-associated virus type 1 (AAV1) as a transgenic vector to deliver VGLUT3 to the cochlea, expression of VGLUT3 is only seen in inner hair cells rather than in all sensory epithelia. (Akil et al., 2012). There was a partial repair of the unconscious startle reflex and a normalization of the auditory brainstem response threshold that was observed 2 weeks after AAV1-VGLUT3 delivery. After the transgenic delivery of VGLUT3, the IHC ribbon synapses of mutant mice also showed improvement in neurotransmission for auditory function. The results of this study demonstrate a successful restoration of hearing in mice by the utilization of transgenic techniques, which represents a significant advance towards the development and application of gene therapy for the treatment of human deafness.

Inner ear sensory epithelial cells are often damaged or lost after the use of the antibiotic gentamicin (Suzuki et al., 2000; Jiang et al., 2016). Adenovirus-mediated overexpression of glial cell line-derived neurotrophic factor (GDNF) can be used to counter this ototoxicity and inner ear injury (Suzuki et al., 2000). A study determined the protective effects of adenovirus-mediated overexpression of GDNF against gentamicin ototoxicity (Suzuki et al., 2000). The results of this study have demonstrated that this therapy can rescue the inner ear structure and function against damage caused by exposure to an ototoxic level of gentamicin (Suzuki et al., 2000).

Recently, there has been an increased interest in exploring the potential of brain derived neurotrophic factor (BDNF) to rescue hearing using adenovirus. In one study, guinea pigs were exposed to noise to induce cochlear damage (Zhai et al., 2011). Guinea pig cochleas were infused with recombinant adenovirus vector expressing BDNF or LacZ recombinant adenovirus vector or artificial perilymph. A significant decrease in ABR thresholds were observed in animals that received BDNF vector compared to LacZ or artificial perilymph group at 8-weeks of cochlear perfusion. In BDNF vector treated group, there was a strong expression of BDNF in all turns of cochlea including the spiral ligament, labium limbi tympanicum and supporting cells. The number of spiral ganglion in BDNF treated group were significantly higher than in LacZ or artificial perilymph treated animals. The results of this study suggest that BDNF exerts protective effects on spiral ganglions in response to cochlear insults such as noise leading to rescue of hearing. However, due to immunogenic and inflammatory potential of adenoviruses, there is a need to design better viral vectors for gene therapy. 
AAV vectors are currently the most preferred choice for delivering inner ear gene therapy, due to their limited toxic and immunogenic effects (Shu et al., 2016; Landegger et al., 2017). Different serotypes of these vectors have been explored, e.g., in an in vivo experiment, AAV3 was found to transduce cochlear IHCs in the basal and middle cochlear regions exclusively with notable efficiency (Lalwani et al., 1996). Another study looked at five AAV vectors of serotypes 1, 2, 5, 6 and 8, and upon injection through the scala media in both normal and severely damaged inner ears, sensory transduction was observed within most cells that make up the inner ear, including sensory hair cells, supporting cells, the auditory nerve, and spiral ligament cells (Kilpatrick et al., 2011). Most recently, 12 different AAV vectors of different serotypes were injected into neonatal and adult mice in vivo, each resulting in cell type specificities and expression levels, as measured by expression of a reporter gene (GFP; Shu et al., 2016). Ten of these serotypes were found to infect neonatal inner ears and eight infected adult inner ears. The hair cells and supporting cells had higher affinities for AAV infection, which makes this method ideal. Unfortunately, it was also noted that while neonatal inner ear delivery of AAV vectors did not adversely affect hearing, adult inner ear injections ultimately resulted in outer hair cell death and a subsequent hearing loss (Shu et al., 2016). Furthermore, the use of AAVs is restricted by the size limit available for inserts (i.e., less than $4.7 \mathrm{~kb}$; Akil et al., 2012). Recently, it has been demonstrated that exosome-associated AAV vectors (exo-AAVs) are efficient carriers of transgenes into cochlear and vestibular hair cells both in vitro and in vivo (György et al., 2017). Exo-AAV vectors outperform conventional $\mathrm{AAV}$ vectors in gene transfer efficiency and are also well tolerated by inner ear tissues. Another study developed a synthetic AAV vector, i.e., Anc80L65, and demonstrated that round window membrane injection of this synthetic vector into mice enables safe and efficient gene transfer to the mammalian inner ear (Landegger et al., 2017). Highly efficient transduction of both inner and outer hair cells was observed in mice. Round window membrane injection was also well tolerated, as indicated by hearing and vestibular function and immunologic parameters. Another study demonstrated that early reintroduction of wild-type harmonin using this synthetic AAV vector, Anc80L65, can lead to recovery of gene and protein expression, restoration of sensory cell function, rescue of complex auditory function and recovery of hearing and balance behavior to near wild-type levels in a mouse model of Usher syndrome type 1c (Pan et al., 2017). There is a hope that AAV will develop to be a central vector to deliver gene therapy for hearing deficits, but there are still significant improvements needed before gene delivery can be a safe and efficient way to deliver therapy to the inner ear.

\section{STEM CELL THERAPIES}

Besides gene therapy, stem cell therapy is an emerging technology with potential applications for the treatment of human diseases. The use of stem cells to assist in the repair of damaged cardiac tissue following a heart attack, to accelerate wound healing in diabetic patients, and treat diseases of the eyes are just a few of the clinical applications of the rapidly developing field of stem cell therapy. The inner ear can be made accessible to placement of exogenous stem cell in the scala tympani or scala media of the cochlea, Rosenthal's canal where the spiral ganglion resides, and into the areas of the vestibular sensory receptors via direct injection through a micro-syringe. Stem cells have the potential to contribute to the repair and restoration of inner ear sensory structures and their sensory ganglia. Stem cells provide protection via direct integration into the damaged receptor or ganglion with the subsequent differentiation of the transplanted stem cells into replacement sensory hair or neuronal cell types.

Using sphere culture methods, a series of experiments demonstrated that both neonatal cochlear and vestibular tissues contained endogenous stem cells. These cells possess the potential to generate hair cell like cells, but only vestibular tissue obtained from adult animals retained the potential to form hair cell like cells within cultured spheres (Oshima et al., 2007, 2009). An in vitro study has shown that murine embryonic stem cells (ESCs) can be induced to initiate stepwise differentiation of both inner ear hair cells and neurons (Koehler et al., 2013). The hair cells formed from these ESCs in a 3-D culture system exhibit functional characteristics of hair cells. In addition, these cells formed specialized synaptic contacts with the sensory neurons that developed within these cultures (Koehler et al., 2013). Further studies of ESCs in the 3-D culture system has revealed that modulation of Wnt signaling with a potent Wnt agonist can enhance the process of differentiation of inner ear sensory tissues within these cultures (DeJonge et al., 2016). These in vitro findings with ESC cultures (Koehler et al., 2013; DeJonge et al., 2016) are in agreement with results from a series of experiments which examined the role that a gene target of Wnt signaling (Lgr5) plays in determining the stemness of support cells located within the neonatal cochlea (Chai et al., 2012; Shi et al., 2012).

A lineage tracing study in neonatal mice has shown that Lgr5 positive inner pillar cells and 3rd row Deiter's cells are the cell types that predominantly produce new outer hair cells (Bramhall et al., 2014). Cells positive for Lgr5 expression were also isolated from neonatal vestibular tissues and were associated with determining the stemness of support cells and their ability to produce new hair cells but these Lgr5 positive cells did not produce any neuronal cells (McLean et al., 2016). This same study revealed that PLP-1 positive glial cell derived from neonatal spiral ganglia explants could act as a neuronal progenitor source and give rise to sensory neurons, glia and oligodendrocytes but not to any hair cells (McLean et al., 2016).

An in vitro study of neural stem cells (NSCs) found within the spiral ganglion identified micro-RNA 124 as a key factor in promoting both neuronal differentiation and neurite outgrowth from the spiral ganglion's NSCs (Jiang et al., 2016). Results from a rat model of spiral ganglion neuronal degeneration also point to the importance of damage-initiated cochlear Schwann cell secretion of Wnt-1 in enhancing the survival of transplanted NSCs and their differentiation into replacement neurons within 
the sensory ganglion ( $\mathrm{He}$ et al., 2014). Another type of stem cell considered as a possible candidate to replace lost spiral ganglion neurons are bone marrow derived mesenchymal stem cells (MSCs; Matsuoka et al., 2007). Experiments in gerbils showed that the direct injection of MSCs into the modiolus of an injured cochlea resulted in the successful transplantation of these stem cells but that injection of MSCs into the scala tympani did not result in the transplantation of the injected cell into the modiolus (Matsuoka et al., 2007).

Induced pluripotent stem cells (iPSCs) of both mouse and human origins have also been evaluated as potential replacement therapies for lost spiral ganglion neurons and both of these iPSC cell types have been shown to express neuronal phenotypes and vesicular glutamate transporter one (VGLUT-1) which identifies glutamatergic neurons (Nishimura et al., 2009; Ishikawa et al., 2015). In addition to these findings, human iPSCs transformed into glutamatergic neurons transplanted into a guinea pig cochlea were found to survive this transplantation if the animal's immune system was suppressed (Ishikawa et al., 2015). Human iPSCs can also be transformed into hair cell like cells in vitro through the use of a step-wise protocol and with the use of basic FGF (bFGF) as an inducing factor (Ohnishi et al., 2015). Of note, the yield of hair cell like cells from this protocol was very low and therefore is not as promising for hair cell replacement as it is for the replacement of spiral ganglion neurons.

NSCs obtained from olfactory epithelium (oe) is an important consideration because they can be obtained from a patient and then possibly used to treat that same patient. An animal study has determined that these oe-NSCs can be used to replace injured or lost spiral ganglion neurons in a rat model of hearing loss (Xu et al., 2016). An excellent source for human MSCs to be use in possible stem cell therapy to treat damaged inner ear sensory receptors and ganglia are cells derived from human umbilical cord: namely, Wharton's Jelly cells, also known as human umbilical cord mesenchymal stromal cells (hUCMSCs; Mellott et al., 2016). One of the main advantages of hUCMSCs is that they retain their ability to differentiate into multiple cell types arising from all three embryonic germ layers (Mellott et al., 2016). These hUCMSCs when treated with a vector expressing Atoh 1 can be induced to differentiate into hair cell like cells that express hair-cell specific markers (Devarajan et al., 2013) making them a possible candidate for the treatment of both hearing loss and balance disorders.

One final approach to cover in the application of stem cells to the treatment of deafness is to use cell cultures of a patient's own stem cells (iPSCs) to model their genetic disease. This approach helps in deciphering the underlying pathogenic mechanisms and then to test cutting edge gene editing methods including CRISPR/Cas9 to develop treatment modalities for the discovered genetic defect (Chen S. et al., 2016; Tang et al., 2016; Hosoya et al., 2017).

\section{GENE EDITING STRATEGIES}

The genome editing technologies using programmable nucleases can modify the genome at a targeted locus and is recognized to be a valuable tool in studying the function of genes associated with hearing loss (Zou et al., 2015; Gurumurthy et al., 2016). These approaches have only recently been applied to study defects in the inner ear, but the goal is that genome editing 1 day could be optimized to restore wild-type sequences in native DNA thereby correcting for gene mutations that adversely affect hearing and balance. There are three major programmable nucleases, which include Zinc finger nucleases (ZFNs), transcriptional activator-like effector nucleases (TALENs), and CRISPR/Cas9 (Zou et al., 2015; Eid and Mahfouz, 2016; Govindan and Ramalingam, 2016; Mei et al., 2016; Torres-Ruiz and RodriguezPerales, 2016; Wang et al., 2016). These nucleases induce a site-specific DNA double-strand break. This break can then be repaired by either homologous or non-homologous mechanisms (Zou et al., 2015; Chandrasegaran and Carroll, 2016; Kim, 2016). Depending on the pathway of repair, one can introduce different mutations at a specific site. ZFNs or TALENs are able to be packaged into viral vectors, targeting supporting cells or hair cells (Gaj et al., 2013). However, the elegant and simple design of the CRISPR/Cas9 system makes this approach more favorable than the other two techniques (Zou et al., 2015; Gurumurthy et al., 2016). The functions of inner ear genes can be efficiently examined by disrupting normal gene alleles via non-homologous end-joining (NHEJ) mechanism in the CRISPR/Cas9 system (Zou et al., 2015). In terms of its validity as a treatment option, CRISPR/Cas9 has the potential to repair gene mutations via homology-directed repair or disrupting dominant mutations via NHEJ (Zou et al., 2015).

Traditional models to study hearing loss in transgenic animals can be laborious and expensive. CRISPR/Cas9 can create deletion models by producing embryonic stem cells exposed to NHEJ or single nucleotide mutation and gene insertion models via homology directed repair (An et al., 2016; Chen J. R. et al., 2016; Markossian and Flamant, 2016; Nakagawa et al., 2016; Wettstein et al., 2016). We have shown earlier that complexes formed from Cas9 and nucleic acid gRNA can be delivered to mouse inner hair cells directly (Zuris et al., 2015). In addition, these complexes were individually examined and were found to induce effective genome edits either by GFP signal knockdown in Atoh1-GFP transgenic mice or by detection of small insertions and deletions of short sequences (indels) via high-throughput sequencing (Zuris et al., 2015). Other advantages with this system are the possibility of editing multiple genes simultaneously as well as the minimal toxic effects when delivering the complex or during the actual editing of the genome. Cas9 and gRNAs have short half-lives, but the genome editing is permanent. Unfortunately, this method is at present limited to only outer hair cells and has not yet been optimized to target genes in inner hair cells effectively. However, there are still considerable concerns about potential off-target effects of editing the genome. There are still no acceptable methods for identifying or preventing the precise off targets effects of genome editing. Current strides are being made in implementing this pioneering technique and given the rapid pace in this field, these complications are likely to be overcome in the near future. 
A recent study utilized the CRISPR/Cas9 knock-in method to confirm a mutation effect that was found in a classical genetic analysis (Miyasaka et al., 2016). The study used Jackson shaker $\left(U s h 1 g^{j s}\right)$ as the mouse model for recessive deafness due to a homozygous mutation of $U s h 1^{g / \text { Sans }}$ and found that heterozygous mice showed early-onset PHL (ePHL) along with progressive stereocilia degeneration involving the outer hair cells. Using traditional genetic analytical methods, they found that ePHL in Ush1gis/+ mice was linked with an interval in chromosome 10. This chromosome includes the gene for cadherin 23, another gene known to cause deafness in humans (Bork et al., 2001). Using the CRISPR/Cas9 knock-in system, mice homozygous for Ush1gjs and mice double heterozygous for an $A$ to $G$ (one base) substitution within the cadherin 23 gene. Ultimately, using this technology, their analyses revealed a relationship between the Ush $1 g$ and Cdh23 genes, such that at least two mutant alleles within these genes will eventually manifest into ePHL (Miyasaka et al., 2016). Recently it has been demonstrated that CRISPR/Cas9-mediated HDR can successfully correct the Cdh23 $3^{\text {ahl }}$ allele in C57BL/6NTac mice, and rescue the associated auditory phenotype (Mianné et al., 2016). The heterozygous Cdh23 (Cdh23 $3^{\text {ahl } / 753 A>G}$ ) mice treated with CRISPR/Cas9 displayed normal hearing thresholds and a full complement of cochlear sensory hair cell stereocilia bundles compared to homozygous C57BL/6NTac mice $\left(C d h 23^{a h l / a h l}\right)$ at 36 weeks of age. It was demonstrated that the CRISPR/Cas9 approach is highly specific, with no lesions identified at any of the predicted off-target sites. These studies provide proof of principle that CRISPR/Cas9 genome editing can be utilized to correct mutations in deafness genes and has the ability to rescue hearing function.

The development of in vitro systems to substantiate gene therapies that were successful in animal models holds great potential for translational of these therapies from the research lab to the clinic. There has been some success in culturing human inner ear tissue in organotypic cultures that can be used to study potential treatment modalities (Kesser et al., 2007). Patients undergoing resection of tumors growing on the vestibulocochlear nerve also have viable vestibular tissue excised. Adenoviral vectors containing genes for wild-type GFP and potassium channel protein KCNQ4 were applied to the sensory epithelia. KCNQ4 is known to cause dominantprogressive hearing loss when mutated (Kubisch et al., 1999; Mittal et al., 2017). Strong expression of an exogenous transgene (GFP) in hair cells and supporting cells was observed, indicating that the adenovirus transfection can drive the expression of a wild-type form of human deafness genes, e.g., KCNQ4. This study ultimately presented an effective experimental way to evaluate gene therapies designed to restore hearing loss and is a useful transition to validate these therapies before human clinical trials can be designed and implemented.

\section{CONCLUSIONS}

Recent advancements in technologies have opened up several promising avenues to combat hearing loss with a great translational potential. However, many challenges still exist that make it extremely difficult to properly regenerate hair cells. Proper orientation, tonotopic arrangement, appropriate integration, as well as adequate innervation of the cells all have to be considered to provide a functional solution to hearing loss. Of the different strategies outlined, gene will require considerable improvement in order to better control gene targeting, editing and expression. AAV are currently the popular choice in delivering these gene therapies, but with the advent of other more sophisticated gene editing technologies like the CRISPR/Cas9 system, it is likely that these newer strategies will also become extremely useful in sensory regeneration research. While the technical capability of these methods have been explored in supporting cells and inner hair cells, there has not been substantial understanding of pathologic mechanisms to advance these strategies into effective therapies. At most, inner ear gene therapy has largely focused on gene replacement or amplification, but these tactics are only effective in recessive deafness. Since some dominant forms of deafness result from single point mutations, gene-editing technologies including CRISPR/Cas9 will become a valuable tool to deliver therapy in the near future.

Due to limited ability of hair cells to regenerate, this aspect of hearing loss will continue to receive the most attention to develop novel treatment modalities. The main therapeutic strategies will tend to implicate resetting the course of the reprogramming of supporting cells to a proliferative progenitor state followed by a differentiation phase where both new hair cells and supporting cells are produced. One other stem cell option may in the future be the ex vivo expansion of a patient's own stem cells and then reintroduction into a damage site such as spiral ganglion. Our comprehension of the underlying mechanisms is not yet complete enough to progress into tangible, working treatments. However, the auditory community working in the field of regenerative medicine is positive that with the evolution of new technologies, treatments for inner ear sensory disorders are sure to emerge.

\section{AUTHOR CONTRIBUTIONS}

RM, DN, APP, LHD, JM, DY, AAE, TRVW and XZL drafted and wrote the manuscript.

\section{ACKNOWLEDGMENTS}

The research work in Prof. Liu's Laboratory is supported by grants R01 DC05575, R01 DC01246, and R01 DC012115 from the National Institutes of Health/National Institute on Deafness and Other Communication Disorders. RM is a recipient of a grant from Hearing Health Foundation (HHF). Professors AAE and TRVW have received funding from MED-EL Corporation. The content is solely the responsibility of the authors and does not necessarily represent the official views of the funding agencies. We are thankful to April Mann for the critical reading of the manuscript. 


\section{REFERENCES}

Ahmed, Z. M., Riazuddin, S., Riazuddin, S., and Wilcox, E. R. (2003). The molecular genetics of Usher syndrome. Clin. Genet. 63, 431-444. doi: 10.1034/j. 1399-0004.2003.00109.x

Ahmed, Z. M., Yousaf, R., Lee, B. C., Khan, S. N., Lee, S., Lee, K., et al. (2011). Functional null mutations of MSRB3 encoding methionine sulfoxide reductase are associated with human deafness DFNB74. Am. J. Hum. Genet. 88, 19-29. doi: 10.1016/j.ajhg.2010.11.010

Akil, O., Seal, R. P., Burke, K., Wang, C., Alemi, A., During, M., et al. (2012). Restoration of hearing in the VGLUT3 knockout mouse using virally-mediated gene therapy. Neuron 75, 283-293. doi: 10.1016/j.neuron.2012.05.019

Alagramam, K. N., Gopal, S. R., Geng, R., Chen, D. H., Nemet, I., Lee, R., et al. (2016). A small molecule mitigates hearing loss in a mouse model of Usher syndrome III. Nat. Chem. Biol. 12, 444-451. doi: 10.1038/nchembio.2069

An, L., Hu, Y., Chang, S., Zhu, X., Ling, P., Zhang, F., et al. (2016). Efficient generation of FVII gene knockout mice using CRISPR/Cas9 nuclease and truncated guided RNAs. Sci. Rep. 6:25199. doi: 10.1038/srep25199

Atkinson, P. J., Wise, A. K., Flynn, B. O., Nayagam, B. A., and Richardson, R. T. (2014). Hair cell regeneration after ATOH1 gene therapy in the cochlea of profoundly deaf adult guinea pigs. PLoS One 9:e102077. doi: 10.1371/journal. pone. 0102077

Baker, K., Brough, D. E., and Staecker, H. (2009). Repair of the vestibular system via adenovector delivery of Atoh1: a potential treatment for balance disorders. Adv. Otorhinolaryngol. 66, 52-63. doi: 10.1159/000218207

Banjara, H., Mungutwar, V., Swarnkar, N., and Patra, P. (2016). Detection of connexion 26 GENE (GJB2) mutations in cases of congenital non syndromic deafness. Indian J. Otolaryngol. Head Neck Surg. 68, 248-253. doi: 10.1007/s12070-015-0950-4

Barr-Gillespie, P. G. (2015). Assembly of hair bundles, an amazing problem for cell biology. Mol. Biol. Cell. 26, 2727-2732. doi: 10.1091/mbc.E14-04-0940

Basch, M. L., Brown, R. M. II, Jen, H. I., and Groves, A. K. (2016). Where hearing starts: the development of the mammalian cochlea. J. Anat. 228, 233-254. doi: 10.1111/joa.12314

Ben Said, M., Grati, M., Ishimoto, T., Zou, B., Chakchouk, I., Ma, Q., et al. (2016). A mutation in SLC22A4 encoding an organic cation transporter expressed in the cochlea strial endothelium causes human recessive non-syndromic hearing loss DFNB60. Hum. Genet. 135, 513-524. doi: 10.1007/s00439-016-1657-7

Ben-Rebeh, I., Grati, M., Bonnet, C., Bouassida, W., Hadjamor, I., Ayadi, H., et al. (2016). Genetic analysis of Tunisian families with Usher syndrome type 1: toward improving early molecular diagnosis. Mol. Vis. 22, 827-835.

Bermingham-McDonogh, O., and Reh, T. A. (2011). Regulated reprogramming in the regeneration of sensory receptor cells. Neuron. 71, 389-405. doi: 10.1016/j. neuron.2011.07.015

Bolz, H. J. (2016). Hereditary hearing loss and its syndromes third edition. Eur. J. Hum. Genet. 24:1650. doi: 10.1038/ejhg.2016.67

Bonnet, C., and El-Amraoui, A. (2012). Usher syndrome (sensorineural deafness and retinitis pigmentosa): pathogenesis, molecular diagnosis and therapeutic approaches. Curr. Opin. Neurol. 25, 42-49. doi: 10.1097/WCO. 0b013e32834ef8b2

Bork, J. M., Peters, L. M., Riazuddin, S., Bernstein, S. L., Ahmed, Z. M., Ness, S. L., et al. (2001). Usher syndrome 1D and nonsyndromic autosomal recessive deafness DFNB12 are caused by allelic mutations of the novel cadherin-like gene CDH23. Am. J. Hum. Genet. 68, 26-37. doi: 10.1086/316954

Boulet, S. L., Boyle, C. A., and Schieve, L. A. (2009). Health care use and health and functional impact of developmental disabilities among US children, 1997-2005. Arch. Pediatr. Adolesc. Med. 163, 19-26. doi: 10.1001/archpediatrics. 2008.506

Bramhall, N. F., Shi, F., Arnold, K., Hochedlinger, K., and Edge, A. S. (2014). Lgr5positive supporting cells generate new hair cells in the postnatal cochlea. Stem Cell Repotrs 2, 311-322. doi: 10.1016/j.stemcr.2014.01.008

Brigande, J. V., Gubbels, S. P., Woessner, D. W., Jungwirth, J. J., and Bresee, C. S. (2009). Electroporation-mediated gene transfer to the developing mouse inner ear. Methods Mol. Biol. 493, 125-139. doi: 10.1007/978-1-59745-523-7 8

Chai, R., Kuo, B., Wang, T., Liaw, E. J., Xia, A., Jan, T. A., et al. (2012). Wnt signaling induces proliferation of sensory precursors in the postnatal mouse cochlea. Proc. Natl. Acad. Sci. U S A 109, 8167-8172. doi: 10.1073/pnas. 1202774109
Chandrasegaran, S., and Carroll, D. (2016). Origins of programmable nucleases for genome engineering. J. Mol. Biol. 428, 963-989. doi: 10.1016/j.jmb. 2015.10.014

Chen, Z. Y. (2006). Cell cycle, differentiation and regeneration: where to begin? Cell Cycle 5, 2609-2612. doi: 10.4161/cc.5.22.3503

Chen, S., Lee, B., Lee, A. Y., Modzelewski, A. J., and He, L. (2016). Highly efficient mouse genome editing by CRISPR ribonucleoprotein electroporation of zygotes. J. Biol. Chem. 291, 14457-14467. doi: 10.1074/jbc.M116. 733154

Chen, J. R., Tang, Z. H., Zheng, J., Shi, H. S., Ding, J., Qian, X. D., et al. (2016). Effects of genetic correction on the differentiation of hair cell-like cells from iPSCs with MYO15A mutation. Cell Death Differ. 23, 1347-1357. doi: 10.1038/cdd.2016.16

Chen, Y., Yu, H., Zhang, Y., Li, W., Lu, N., Ni, W., et al. (2013). Cotransfection of Pax2 and Math1 promote in situ cochlear hair cell regeneration after neomycin insult. Sci. Rep. 3:2996. doi: 10.1038/srep02996

Contrera, K. J., Betz, J., Deal, J. A., Choi, J. S., Ayonayon, H. N., Harris, T., et al. (2016). Association of hearing impairment and emotional vitality in older adults. J. Gerontol. B Psychol. Sci. Soc. Sci. 71, 400-404 doi: 10.1093/geronb/gbw005

Cox, B. C., Chai, R., Lenoir, A., Liu, Z., Zhang, L., Nguyen, D.-H., et al. (2014) Spontaneous hair cell regeneration in the neonatal mouse cochlea in vivo. Development 141, 816-829. doi: 10.1242/dev.103036

DeJonge, R. E., Liu, X. P., Deig, C. R., Heller, S., Koehler, K. R., and Hashino, E. (2016). Modulation of wnt signaling enhances inner ear organoid development in 3D culture. PLoS One 11:e0162508. doi: 10.1371/journal.pone. 0162508

Depreux, F. F., Wang, L., Jiang, H., Jodelka, F. M., Rosencrans, R. F., Rigo, F., et al (2016). Antisense oligonucleotides delivered to the amniotic cavity in utero modulate gene expression in the postnatal mouse. Nucleic Acids Res. 44 9519-9529. doi: 10.1093/nar/gkw867

Devarajan, K., Forrest, M. L., Detamore, M. S., and Staecker, H. (2013) Adenovector-mediated gene delivery to human umbilical cord mesenchymal stromal cells induces inner ear cell phenotype. Cell. Reprogram. 15, 43-54. doi: 10.1089/cell.2011.0097

Du, Y., Huang, L., Cheng, X., Zhao, L., Ruan, Y., and Ni, T. (2016). Analysis of p.V37I compound heterozygous mutations in the GJB2 gene in Chinese infants and young children. Biosci. Trends 10, 220-226. doi: 10.5582/bst.2016. 01096

Eid, A., and Mahfouz, M. M. (2016). Genome editing: the road of CRISPR/Cas9 from bench to clinic. Exp. Mol. Med. 48:e265. doi: 10.1038/emm. 2016.111

El-Amraoui, A., and Petit, C. (2014). The retinal phenotype of Usher syndrome: pathophysiological insights from animal models. C. R. Biol. 337, 167-177. doi: 10.1016/j.crvi.2013.12.004

Emmett, S. D., and Francis, H. W. (2015). The socioeconomic impact of hearing loss in U.S. adults. Otol. Neurotol. 36, 545-550. doi: 10.1097/MAO. 0000000000000562

Friedman, T. B., Schultz, J. M., Ahmed, Z. M., Tsilou, E. T., and Brewer, C. C. (2011). Usher syndrome: hearing loss with vision loss. Adv. Otorhinolaryngol. 70, 56-65. doi: 10.1159/000322473

Furness, D. N. (2015). Molecular basis of hair cell loss. Cell Tissue Res. 361, 387-399. doi: 10.1007/s00441-015-2113-z

Gaj, T., Gersbach, C. A., and Barbas, C. F. III (2013). ZFN, TALEN, and CRISPR/Cas-based methods for genome engineering. Trends Biotechnol. 31, 397-405. doi: 10.1016/j.tibtech.2013.04.004

Géléoc, G. S. G., and Holt, J. R. (2014). Sound strategies for hearing restoration Science 344:1241062. doi: 10.1126/science.1241062

Goman, A. M., Reed, N. S., and Lin, F. R. (2017). Addressing estimated hearing loss in adults in 2060. JAMA Otolaryngol. Head Neck Surg. doi: 10.1001/jamaoto. 2016.4642 [Epub ahead of print].

Gomes, M. M., Wang, L., Jiang, H., Kahl, C. A., and Brigande, J. V. (2016). A rapid, cost-effective method to prepare recombinant adeno-associated virus for efficient gene transfer to the developing mouse inner ear. Methods Mol. Biol. 1427, 43-57. doi: 10.1007/978-1-4939-3615-1_3

Goodall, A. F., and Siddiq, M. A. (2015). Current understanding of the pathogenesis of autoimmune inner ear disease: a review. Clin. Otolaryngol. 40, 412-419. doi: 10.1111/coa.12432 
Gopal, S. R., Chen, D. H., Chou, S. W., Zang, J., Neuhauss, S. C., Stepanyan, R., et al. (2015). Zebrafish models for the mechanosensory hair cell dysfunction in usher syndrome 3 reveal that clarin-1 is an essential hair bundle protein. J. Neurosci. 35, 10188-10201. doi: 10.1523/JNEUROSCI.1096-15.2015

Goutman, J. D., Elgoyhen, A. B., and Gómez-Casati, M. E. (2015). Cochlear hair cells: the sound-sensing machines. FEBS Lett. 589, 3354-3361. doi: 10.1016/j. febslet.2015.08.030

Govindan, G., and Ramalingam, S. (2016). Programmable site-specific nucleases for targeted genome engineering in higher eukaryotes. J. Cell. Physiol. 231, 2380-2392. doi: $10.1002 /$ jcp. 25367

Gubbels, S. P., Woessner, D. W., Mitchell, J. C., Ricci, A. J., and Brigande, J. V. (2008). Functional auditory hair cells produced in the mammalian cochlea by in utero gene transfer. Nature 455, 537-541. doi: 10.1038/nature07265

Gurumurthy, C. B., Grati, M., Ohtsuka, M., Schilit, S. L., Quadros, R. M., and Liu, X. Z. (2016). CRISPR: a versatile tool for both forward and reverse genetics research. Hum. Genet. 135, 971-976. doi: 10.1007/s00439-016-1704-4

György, B., Sage, C., Indzhykulian, A. A., Scheffer, D. I., Brisson, A. R., Tan, S., et al. (2017). Rescue of hearing by gene delivery to inner-ear hair cells using exosome-associated AAV. Mol. Ther. 25, 379-391. doi: 10.1016/j.ymthe.2016. 12.010

Hartel, B. P., Agterberg, M. J., Snik, A. F., Kunst, H. P., van Opstal, A. J., Bosman, A. J., et al. (2017). Hearing aid fitting for visual and hearing impaired patients with Usher Syndrome type IIa. Clin. Otolaryngol. 42, 805-814. doi: 10.1111/coa.12775

He, Y., Zhang, P. Z., Sun, D., Mi, W. J., Zhang, X. Y., Cui, Y., et al. (2014). Wnt1 from cochlear schwann cells enhances neuronal differentiation of transplanted neural stem cells in a rat spiral ganglion neuron degeneration model. Cell. Transplant. 23, 747-760. doi: 10.3727/096368913x669761

Helvik, A. S., Krokstad, S., and Tambs, K. (2009). Socioeconomic inequalities in hearing loss in a healthy population sample: the HUNT study. Am. J. Public Health 99, 1376-1378. doi: 10.2105/AJPH.2007.133215

Homans, N. C., Metselaar, R. M., Dingemanse, J. G., van der Schroeff, M. P., Brocaar, M. P., Wieringa, M. H., et al. (2017). Prevalence of age-related hearing loss, including sex differences, in older adults in a large cohort study. Laryngoscope 127, 725-730. doi: 10.1002/lary.26150

Hosoya, M., Fujioka, M., Sone, T., Okamoto, S., Akamatsu, W., and Ukai, H. (2017). Cochlear cell modeling using disease-specific iPSCs unveils a degenerative phenotype and suggests treatments for congenital progressive hearing loss. Cell. Rep. 18, 68-81. doi: 10.1016/j.celrep.2016.12.020

Hu, Z., and Ulfendahl, M. (2013). The potential of stem cells for the restoration of auditory function in humans. Regen. Med. 8, 309-318. doi: 10.2217/rme.13.32

Iizuka, T., Kamiya, K., Gotoh, S., Sugitani, Y., Suzuki, M., Noda, T., et al. (2015). Perinatal Gjb2 gene transfer rescues hearing in a mouse model of hereditary deafness. Hum. Mol. Genet. 24, 3651-3661. doi: 10.1093/hmg/ddv109

Ishikawa, M., Ohnishi, H., Skerleva, D., Sakamoto, T., Yamamoto, N., Hotta, A., et al. (2015). Transplantation of neurons derived from human iPS cells cultured on collagen matrix into guinea-pig cochleae. J. Tissue Eng. Regen. Med. 11, 1766-1778. doi: 10.1002/term.2072

Izumikawa, M., Minoda, R., Kawamoto, K., Abrashkin, K. A., Swiderski, D. L., Dolan, D. F., et al. (2005). Auditory hair cell replacement and hearing improvement by Atoh1 gene therapy in deaf mammals. Nat. Med. 11, 271-276. doi: $10.1038 / \mathrm{nm} 1193$

Jeon, S. J., Fujioka, M., Kim, S. C., and Edge, A. S. (2011). Notch signaling alters sensory or neuronal cell fate specification of inner ear stem cells. J. Neurosci. 31, 8351-8358. doi: 10.1523/JNEUROSCI.6366-10.2011

Jiang, D., Du, J., Zhang, X., Zhou, W., Zong, L., Dong, C., et al. (2016). miR124 promotes the neuronal differentiation of mouse inner ear neural stem cells. Int. J. Mol. Med. 38, 1367-1376. doi: 10.3892/ijmm.2016.2751

Jiang, H., Wang, L., Beier, K. T., Cepko, C. L., Fekete, D. M., and Brigande, J. V. (2013). Lineage analysis of the late otocyst stage mouse inner ear by transuterine microinjection of a retroviral vector encoding alkaline phosphatase and an oligonucleotide library. PLoS One 8:e69314. doi: 10.1371/journal.pone.0069314

Karavitaki, K. D., and Corey, D. P. (2010). Sliding adhesion confers coherent motion to hair cell stereocilia and parallel gating to transduction channels. J. Neurosci. 30, 9051-9063. doi: 10.1523/JNEUROSCI.4864-09.2010

Kazmierczak, P., and Muller, U. (2012). Sensing sound: molecules that orchestrate mechanotransduction by hair cells. Trends Neurosci. 35, 220-229. doi: 10.1016/j.tins.2011.10.007
Kesser, B. W., Hashisaki, G. T., Fletcher, K., Eppard, H., and Holt, J. R. (2007). An in vitro model system to study gene therapy in the human inner ear. Gene Ther. 14, 1121-1131. doi: 10.1038/sj.gt.3302980

Khalin, I., Alyautdin, R., Kocherga, G., and Bakar, M. A. (2015). Targeted delivery of brain-derived neurotrophic factor for the treatment of blindness and deafness. Int. J. Nanomedicine 10, 3245-3267. doi: 10.2147/IJN . S77480

Kilpatrick, L. A., Li, Q., Yang, J., Goddard, J. C., Fekete, D. M., and Lang, H. (2011). Adeno-associated virus-mediated gene delivery into the scala media of the normal and deafened adult mouse ear. Gene Ther. 18, 569-578. doi: 10.1038/gt. 2010.175

Kim, J. S. (2016). Genome editing comes of age. Nat. Protoc. 11, 1573-1578. doi: 10.1038/nprot.2016.104

Kim, M. A., Cho, H. J., Bae, S. H., Lee, B., Oh, S. K., Kwon, T. J., et al. (2016). Methionine sulfoxide reductase B3-targeted in utero gene therapy rescues hearing function in a mouse model of congenital sensorineural hearing loss. Antioxid. Redox Signal. 24, 590-602. doi: 10.1089/ars.2015.6442

Koehler, K. R., Mikosz, A. M., Molosh, A. I., Patel, D., and Hashino, E. (2013). Generation of inner ear sensory epithelia from pluripotent stem cells in 3D culture. Nature 500, 217-221. doi: 10.1038/nature12298

Koh, S. B., Mascalchi, P., Rodriguez, E., Lin, Y., Jodrell, D. I., Richards, F. M., et al. (2017). A quantitative FastFUCCI assay defines cell cycle dynamics at a single-cell level. J. Cell Sci. 130, 512-520. doi: 10.1242/jcs.195164

Kubisch, C., Schroeder, B. C., Friedrich, T., Lütjohann, B., El-Amraoui, A., Marlin, S., et al. (1999). KCNQ4, a novel potassium channel expressed in sensory outer hair cells, is mutated in dominant deafness. Cell 96, 437-446. doi: 10.1016/s0092-8674(00)80556-5

Kuo, B. R., Baldwin, E. M., Layman, W. S., Taketo, M. M., and Zuo, J. (2015). In vivo cochlear hair cell generation and survival by coactivation of $\beta$-catenin and atoh1. J. Neurosci. 35, 10786-10798. doi: 10.1523/JNEUROSCI. 0967-15.2015

Kwon, T. J., Cho, H. J., Kim, U. K., Lee, E., Oh, S. K., Bok, J., et al. (2014). Methionine sulfoxide reductase B3 deficiency causes hearing loss due to stereocilia degeneration and apoptotic cell death in cochlear hair cells. Hum. Mol. Genet. 23, 1591-1601. doi: 10.1093/hmg/ddt549

Lalwani, A., Walsh, B., Reilly, P., Muzyczka, N., and Mhatre, A. (1996). Development of in vivo gene therapy for hearing disorders: introduction of adeno-associated virus into the cochlea of the guinea pig. Gene Ther. 3 , $588-592$.

Landegger, L. D., Pan, B., Askew, C., Wassmer, S. J., Gluck, S. D., Galvin, A., et al. (2017). A synthetic AAV vector enables safe and efficient gene transfer to the mammalian inner ear. Nat. Biotechnol. 35, 280-284. doi: 10.1038/nbt.3781

Leake, P. A., Stakhovskaya, O., Hetherington, A., Rebscher, S. J., and Bonham, B. (2013). Effects of brain-derived neurotrophic factor (BDNF) and electrical stimulation on survival and function of cochlear spiral ganglion neurons in deafened, developing cats. J. Assoc. Res. Otolaryngol. 14, 187-211. doi: 10.1007/s10162-013-0372-5

Lee, Y., Kim, H. R., and Ahn, S. C. (2015). Vesicular glutamate transporter 3 is strongly upregulated in cochlear inner hair cells and spiral ganglion cells of developing circling mice. Neurosci. Lett. 584, 320-324. doi: 10.1016/j.neulet. 2014.10.053

Lentz, J. J., Jodelka, F. M., Hinrich, A. J., McCaffrey, K. E., Farris, H. E., Spalitta, M. J., et al. (2013). Rescue of hearing and vestibular function by antisense oligonucleotides in a mouse model of human deafness. Nat. Med. 19, 345-350. doi: $10.1038 / \mathrm{nm} .3106$

Li, W., Wu, J., Yang, J., Sun, S., Chai, R., Chen, Z. Y., et al. (2015). Notch inhibition induces mitotically generated hair cells in mammalian cochleae via activating the Wnt pathway. Proc. Natl. Acad. Sci. U S A 112, 166-171. doi: 10.1073/pnas. 1415901112

Li, C. M., Zhang, X., Hoffman, H. J., Cotch, M. F., Themann, C. L., and Wilson, M. R. (2014). Hearing impairment associated with depression in US adults, National Health and Nutrition Examination Survey 2005-2010. JAMA Otolaryngol. Head Neck Surg. 140, 293-302. doi: 10.1001/jamaoto. 2014.42

Mantela, J., Jiang, Z., Ylikoski, J., Fritzsch, B., Zacksenhaus, E., and Pirvola, U. (2005). The retinoblastoma gene pathway regulates the postmitotic state of hair cells of the mouse inner ear. Development 132, 2377-2388. doi: 10.1242/dev. 01834 
Markossian, S., and Flamant, F. (2016). CRISPR/Cas9: a breakthrough in generating mouse models for endocrinologists. J. Mol. Endocrinol. 57, R81-R92. doi: 10.1530/JME-15-0305

Mathur, P., and Yang, J. (2015). Usher syndrome: hearing loss, retinal degeneration and associated abnormalities. Biochim. Biophys. Acta 1852, 406-420. doi: 10.1016/j.bbadis.2014.11.020

Matsuoka, A. J., Kondo, T., Miyamoto, R. T., and Hashino, E. (2007). Enhanced survival of bone-marrow-derived pluripotent stem cells in an animal model of auditory neuropathy. Laryngoscope 117, 1629-1635. doi: 10.1097/MLG. ob013e31806bf282

McLean, W. J., McLean, D. T., Eatock, R. A., and Edge, A. S. (2016). Distinct capacity for differentiation to inner ear cell types by progenitor cells of the cochlea and vestibular organs. Development 143, 4381-4393. doi: 10.1242/dev. 139840

Mei, Y., Wang, Y., Chen, H., Sun, Z. S., and Ju, X. D. (2016). Recent progress in CRISPR/Cas9 technology. J. Genet. Genomics 43, 63-75. doi: 10.1016/j.jgg. 2016.01.001

Mellott, A. J., Detamore, M. S., and Staecker, H. (2016). The use of human Wharton's jelly cells for cochlear tissue engineering. Methods Mol. Biol. 1427, 319-345. doi: 10.1007/978-1-4939-3615-1_19

Mianné, J., Chessum, L., Kumar, S., Aguilar, C., Codner, G., Hutchison, M., et al. (2016). Correction of the auditory phenotype in C57BL/6N mice via CRISPR/Cas9-mediated homology directed repair. Genome Med. 8:16. doi: 10.1186/s13073-016-0273-4

Mielczarek, M., Zakrzewska, A., and Olszewski, J. (2016). GJB2 sequencing in deaf and profound sensorineural hearing loss children. Otolaryngol. Pol. 70, 21-25. doi: 10.5604/00306657.1199992

Mijovic, T., Zeitouni, A., and Colmegna, I. (2013). Autoimmune sensorineural hearing loss: the otology-rheumatology interface. Rheumatology (Oxford) 52, 780-789. doi: 10.1093/rheumatology/ket009

Miller, J. M., Miller, A. L., Yamagata, T., Bredberg, G., and Altschuler, R. A. (2002). Protection and regrowth of the auditory nerve after deafness: neurotrophins, antioxidants and depolarization are effective in vivo. Audiol. Neurootol. 7, 175-179. doi: 10.1159/000058306

Mittal, R., Aranke, M., Debs, L. H., Nguyen, D., Patel, A. P., Grati, M., et al. (2017). Indispensable role of ion channels and transporters in the auditory system. J. Cell. Physiol. 232, 743-758. doi: 10.1002/jcp.25631

Mittal, R., Chan, B., Grati, M., Mittal, J., Patel, K., Debs, L. H., et al. (2016). Molecular structure and regulation of $\mathrm{P} 2 \mathrm{X}$ receptors with a special emphasis on the role of P2X2 in the auditory system. J. Cell. Physiol. 231, 1656-1670. doi: $10.1002 /$ jcp. 25274

Mittal, R., Patel, K., Mittal, J., Chan, B., Yan, D., Grati, M., et al. (2015). Association of PRPS1 mutations with disease phenotypes. Dis. Markers 2015:127013. doi: 10.1155/2015/127013

Miyasaka, Y., Shitara, H., Suzuki, S., Yoshimoto, S., Seki, Y., Ohshiba, Y., et al. (2016). Heterozygous mutation of Ushlg/Sans in mice causes earlyonset progressive hearing loss, which is recovered by reconstituting the strain-specific mutation in Cdh23. Hum. Mol. Genet. 25, 2045-2059. doi: $10.1093 / \mathrm{hmg} / \mathrm{ddw} 078$

Mizutari, K., Fujioka, M., Hosoya, M., Bramhall, N., Okano, H. J., Okano, H., et al. (2013). Notch inhibition induces cochlear hair cell regeneration and recovery of hearing after acoustic trauma. Neuron 77, 58-69. doi: 10.1016/j.neuron.2012. 10.032

Moctar, E. C., Riahi, Z., El Hachmi, H., Veten, F., Meiloud, G., Bonnet, C., et al. (2016). Etiology and associated GJB2 mutations in Mauritanian children with non-syndromic hearing loss. Eur. Arch. Otorhinolaryngol. 273, 3693-3698. doi: $10.1007 / \mathrm{s} 00405-016-4036-\mathrm{z}$

Moser, T., and Starr, A. (2016). Auditory neuropathy-neural and synaptic mechanisms. Nat. Rev. Neurol. 12, 135-149. doi: 10.1038/nrneurol. 2016.10

Mulvaney, J. F., Thompkins, C., Noda, T., Nishimura, K., Sun, W. W., Lin, S. Y., et al. (2016). Kremen1 regulates mechanosensory hair cell development in the mammalian cochlea and the zebrafish lateral line. Sci. Rep. 6:31668. doi: $10.1038 /$ srep31668

Münster-Wandowski, A., Zander, J. F., Richter, K., and Ahnert-Hilger, G. (2016). Co-existence of functionally different vesicular neurotransmitter transporters. Front. Synaptic. Neurosci. 8:4. doi: 10.3389/fnsyn.2016. 00004
Nakagawa, Y., Oikawa, F., Mizuno, S., Ohno, H., Yagishita, Y., Satoh, A., et al. (2016). Hyperlipidemia and hepatitis in liver-specific CREB3L3 knockout mice generated using a one-step CRISPR/Cas9 system. Sci. Rep. 6:27857. doi: $10.1038 /$ srep27857

Nakamura, T., Nakamura, T., and Matsumoto, K. (2008). The functions and possible significance of Kremen as the gatekeeper of Wnt signalling in development and pathology. J. Cell. Mol. Med. 12, 391-408. doi: 10.1111/j.15824934.2007.00201.x

Niclasen, J., Obel, C., Guldager, C., Pleinert, S., and Dammeyer, J. (2016). Associations between childhood hearing loss and behavioural and academic difficulties: a Danish cohort study. Int. J. Pediatr. Otorhinolaryngol. 90, 91-98. doi: 10.1016/j.ijporl.2016.09.002

Nishimura, K., Nakagawa, T., Ono, K., Ogita, H., Sakamoto, T., Yamamoto, N., et al. (2009). Transplantation of mouse induced pluripotent stem cells into the cochlea. Neuroreport 20, 1250-1254. doi: 10.1097/WNR.0b013e3283 $2 \mathrm{ff} 287$

Obholzer, N., Wolfson, S., Trapani, J. G., Mo, W., Nechiporuk, A., BuschNentwich, E., et al. (2008). Vesicular glutamate transporter 3 is required for synaptic transmission in zebrafish hair cells. J. Neurosci. 28, 2110-2118. doi: 10.1523/jneurosci.5230-07.2008

Ohnishi, H., Skerleva, D., Kitajiri, S., Sakamoto, T., Yamamoto, N., Ito, J., et al. (2015). Limited hair cell induction from human induced pluripotent stem cells using a simple stepwise method. Neurosci. Lett. 599, 49-54. doi: 10.1016/j. neulet.2015.05.032

Olusanya, B. O., Neumann, K. J., and Saunders, J. E. (2014). The global burden of disabling hearing impairment: a call to action. Bull. World Health Organ. 92, 367-373. doi: 10.2471/BLT.13.128728

Oshima, K., Grimm, C. M., Corrales, C. E., Senn, P., Martinez Monedero, R., Géléoc, G. S., et al. (2007). Differential distribution of stem cells in the auditory and vestibular organs of the inner ear. J. Assoc. Res. Otolaryngol. 8, 18-31. doi: 10.1007/s10162-006-0058-3

Oshima, K., Senn, P., and Heller, S. (2009). Isolation of sphere-forming stem cells from the mouse inner ear. Methods Mol. Biol. 493, 141-162. doi: 10.1007/9781-59745-523-7_9

Pan, B., Askew, C., Galvin, A., Heman-Ackah, S., Asai, Y., Indzhykulian, A. A., et al. (2017). Gene therapy restores auditory and vestibular function in a mouse model of Usher syndrome type 1c. Nat. Biotechnol. 35, 264-272. doi: 10.1038/nbt.3801

Qing, J., Zhou, Y., Lai, R., Hu, P., Ding, Y., Wu, W., et al. (2015). Prevalence of mutations in GJB2, SLC26A4, and mtDNA in children with severe or profound sensorineural hearing loss in southwestern China. Genet. Test. Mol. Biomarkers 19, 52-58. doi: 10.1089/gtmb.201 4.0241

Roccio, M., Hahnewald, S., Perny, M., and Senn, P. (2015). Cell cycle reactivation of cochlear progenitor cells in neonatal FUCCI mice by a GSK3 small molecule inhibitor. Sci. Rep. 5:17886. doi: 10.1038/srep17886

Roland, L., Fischer, C., Tran, K., Rachakonda, T., Kallogjeri, D., and Lieu, J. E. (2016). Quality of life in children with hearing impairment: systematic review and meta-analysis. Otolaryngol. Head Neck Surg. 155, 208-219. doi: 10.1177/0194599816640485

Rousset, F., Carnesecchi, S., Senn, P., and Krause, K.-H. (2015). NOX3-Targeted therapies for inner ear pathologies. Curr. Pharm. Des. 21, 5977-5987. doi: $10.2174 / 1381612821666151029112421$

Ruel, J., Emery, S., Nouvian, R., Bersot, T., Amilhon, B., Van Rybroek, J. M., et al. (2008). Impairment of SLC17A8 encoding vesicular glutamate transporter-3, VGLUT3, underlies nonsyndromic deafness DFNA25 and inner hair cell dysfunction in null mice. Am. J. Hum. Genet. 83, 278-292. doi: 10.1016/j.ajhg. 2008.07.008

Sage, C., Huang, M., Karimi, K., Gutierrez, G., Vollrath, M. A., Zhang, D. S., et al. (2005). Proliferation of functional hair cells in vivo in the absence of the retinoblastoma protein. Science 307, 1114-1118. doi: 10.1126/science. 1106642

Seal, R. P., Akil, O., Yi, E., Weber, C. M., Grant, L., Yoo, J., et al. (2008). Sensorineural deafness and seizures in mice lacking vesicular glutamate transporter 3. Neuron 57, 263-275. doi: 10.1016/j.neuron.2007.11.032

Seal, R. P., and Edwards, R. H. (2006). The diverse roles of vesicular glutamate transporter 3. Handb. Exp. Pharmacol. 175, 137-150. doi: 10.1007/3-54029784-7_7 
Shen, X., Liu, F., Wang, Y., Wang, H., Ma, J., Xia, W., et al. (2015). Downregulation of msrb3 and destruction of normal auditory system development through hair cell apoptosis in zebrafish. Int. J. Dev. Biol. 59, 195-203. doi: $10.1387 / \mathrm{ijdb} .140200 \mathrm{md}$

Shi, F., Kempfle, J., and Edge, A. S. B. (2012). Wnt responsive Lgr5-expressing stem cells are hair cell progenitors in the cochlea. J. Neurosci. 32, 9639-9648. doi: 10.1523/JNEUROSCI.1064-12.2012

Shibata, S. B., Cortez, S. R., Wiler, J. A., Swiderski, D. L., and Raphael, Y. (2012). Hyaluronic acid enhances gene delivery into the cochlea. Hum. Gene Ther. 23, 302-310. doi: 10.1089/hum.2011.086

Shinohara, T., Bredberg, G., Ulfendahl, M., Pyykkö, I., Olivius, N. P., Kaksonen, R., et al. (2002). Neurotrophic factor intervention restores auditory function in deafened animals. Proc. Natl. Acad. Sci. U S A 99, 1657-1660. doi: 10.1073/pnas. 032677999

Shou, J., Zheng, J. L., and Gao, W. Q. (2003). Robust generation of new hair cells in the mature mammalian inner ear by adenoviral expression of Hath1. Mol. Cell. Neurosci. 23, 169-179. doi: 10.1016/s1044-7431(03)0 0066-6

Shu, Y., Tao, Y., Wang, Z., Tang, Y., Li, H., Dai, P., et al. (2016). Identification of adeno-associated viral vectors that target neonatal and adult mammalian inner ear cell subtypes. Hum. Gene Ther. 27, 687-699. doi: 10.1089/hum.20 16.053

Sienknecht, U. J. (2015). Current concepts of hair cell differentiation and planar cell polarity in inner ear sensory organs. Cell Tissue Res. 361, 25-32. doi: 10.1007/s00441-015-2200-1

Sly, D. J., Hampson, A. J., Minter, R. L., Heffer, L. F., Li, J., Millard, R. E., et al. (2012). Brain-derived neurotrophic factor modulates auditory function in the hearing cochlea. J. Assoc. Res. Otolaryngol. 13, 1-16. doi: 10.1007/s10162-0110297-9

Smith, L. S. (2015). Tune into safety for hearing-impaired patients. Nursing 45 , 64-66. doi: 10.1097/01.NURSE.0000461842.08906.27

Stevenson, J., Kreppner, J., Pimperton, H., Worsfold, S., and Kennedy, C. (2015). Emotional and behavioural difficulties in children and adolescents with hearing impairment: a systematic review and meta-analysis. Eur. Child Adolesc. Psychiatry 24, 477-496. doi: 10.1007/s00787-0150697-1

Sun, L. W., Johnson, R. D., Langlo, C. S., Cooper, R. F., Razeen, M. M., Russillo, M. C., et al. (2016). Assessing photoreceptor structure in retinitis pigmentosa and usher syndrome. Invest. Ophthalmol. Vis. Sci. 57, 2428-2442. doi: $10.1167 /$ iovs.15-18246

Suzuki, M., Yagi, M., Brown, J. N., Miller, A. L., Miller, J. M., and Raphael, Y. (2000). Effect of transgenic GDNF expression on gentamicin-induced cochlear and vestibular toxicity. Gene Ther. 7, 1046-1054. doi: 10.1038/sj.gt.33 01180

Tang, Z. H., Chen, J. R., Zheng, J., Shi, H. S., Ding, J., Qian, X. D., et al. (2016). Genetic correction of induced pluripotent stem cells from a deaf patient with MYO7A mutation results in morphologic and functional recovery of the derived hair cell-like cells. Stem Cells Transl. Med. 5, 561-571. doi: $10.5966 /$ sctm.2015-0252

Tarang, S., Doi, S. M., Gurumurthy, C. B., Harms, D., Quadros, R., and Rocha-Sanchez, S. M. (2015). Generation of a Retinoblastoma (Rb)1inducible dominant-negative (DN) mouse model. Front. Cell. Neurosci. 9:52. doi: $10.3389 /$ fncel.2015.00052

Torres-Ruiz, R., and Rodriguez-Perales, S. (2016). CRISPR-Cas9 technology: applications and human disease modelling. Brief Funct. Genomics 16, 4-12. doi: 10.1093/bfgp/elw025

Tseng, C. C., Hu, L. Y., Liu, M. E., Yang, A. C., Shen, C. C., and Tsai, S. J. (2016). Risk of depressive disorders following sudden sensorineural hearing loss: a nationwide population-based retrospective cohort study. J. Affect. Disord. 197, 94-99. doi: 10.1016/j.jad.2016.03.020

van As, J. W., van den Berg, H., and van Dalen, E. C. (2016). Platinum-induced hearing loss after treatment for childhood cancer. Cochrane Database Syst. Rev. 8:CD010181. doi: 10.1002/14651858.CD010885

Venkatesh, M. D., Moorchung, N., and Puri, B. (2015). Genetics of non syndromic hearing loss. Med. J. Armed Forces India 71, 363-368. doi: 10.1016/j.mjafi.2015. 07.003

Verpy, E., Leibovici, M., Michalski, N., Goodyear, R. J., Houdon, C., Weil, D., et al. (2011). Stereocilin connects outer hair cell stereocilia to one another and to the tectorial membrane. J. Comp. Neurol. 519, 194-210. doi: 10.1002/cne.22509
Wang, L., Jiang, H., and Brigande, J. V. (2012). Gene transfer to the developing mouse inner ear by in vivo electroporation. J. Vis. Exp. 64:3653. doi: $10.3791 / 3653$

Wang, H., La Russa, M., and Qi, L. S. (2016). CRISPR/Cas9 in genome editing and beyond. Ann. Rev. Biochem. 85, 227-264. doi: 10.1146/annurev-biochem060815-014607

Waqas, M., Zhang, S., He, Z., Tang, M., and Chai, R. (2016). Role of Wnt and Notch signaling in regulating hair cell regeneration in the cochlea. Front. Med. 10, 237-249. doi: 10.1007/s11684-0160464-9

Wettstein, R., Bodak, M., and Ciaudo, C. (2016). Generation of a knockout mouse embryonic stem cell line using a paired CRISPR/Cas9 genome engineering tool. Methods Mol. Biol. 1341, 321-343. doi: 10.1007/7651_20 $15 \_213$

White, P. M., Doetzlhofer, A., Lee, Y. S., Groves, A. K., and Segil, N. (2006). Mammalian cochlear supporting cells can divide and transdifferentiate into hair cells. Nature 441, 984-987. doi: 10.1038/nature 04849

Whitfield, T. T. (2015). Development of the inner ear. Curr. Opin. Genet. Dev. 32, 112-118. doi: 10.1016/j.gde.2015.02.006

WHO. (2013). Multi-Country Assessment of National Capacity to Provide Hearing Care. Geneva, Switzerland: World Health Organization.

Woods, C., Montcouquiol, M., and Kelley, M. W. (2004). Math1 regulates development of the sensory epithelium in the mammalian cochlea. Nat. Neurosci. 7, 1310-1318. doi: 10.1038/nn1349

Xia, W., Liu, F., and Ma, D. (2016). Research progress in pathogenic genes of hereditary non-syndromic mid-frequency deafness. Front. Med. 10, 137-142. doi: 10.1007/s11684-016-0449-8

Xia, H., Xu, H., Deng, X., Yuan, L., Xiong, W., Yang, Z., et al. (2016). Compound heterozygous GJB2 mutations associated to a consanguineous Han family with autosomal recessive non-syndromic hearing loss. Acta Otolaryngol. 136, 782-785. doi: 10.3109/00016489.2016.1 157727

Xu, Y. P., Shan, X. D., Liu, Y. Y., Pu, Y., Wang, C. Y., Tao, Q. L., et al. (2016). Olfactory epithelium neural stem cell implantation restores noiseinduced hearing loss in rats. Neurosci. Lett. 616, 19-25. doi: 10.1016/j.neulet. 2016.01.016

Yamagata, T., Miller, J. M., Ulfendahl, M., Olivius, N. P., Altschuler, R. A., Pyykkö, I., et al. (2004). Delayed neurotrophic treatment preserves nerve survival and electrophysiological responsiveness in neomycindeafened guinea pigs. J. Neurosci. Res. 78, 75-86. doi: 10.1002/jnr. 20239

Yan, D., Kannan-Sundhari, A., Vishwanath, S., Qing, J., Mittal, R. Kameswaran, M., et al. (2015). The genetic basis of nonsyndromic hearing loss in Indian and Pakistani populations. Genet. Test. Mol. Biomarkers 19, 512-527. doi: 10.1089/gtmb.201 5.0023

Yan, D., and Liu, X. Z. (2008). Cochlear molecules and hereditary deafness. Front. Biosci. 13, 4972-4983. doi: 10.2741/3056

Yan, D., and Liu, X. Z. (2010). Genetics and pathological mechanisms of Usher syndrome. J. Hum. Genet. 55, 327-335. doi: 10.1038/jhg.2010.29

Yan, D., Tekin, D., Bademci, G., Foster, J. II, Cengiz, F. B., Kannan-Sundhari, A., et al. (2016). Spectrum of DNA variants for non-syndromic deafness in a large cohort from multiple continents. Hum. Genet. 135, 953-961. doi: 10.1007/s00439-016-1697-z

Yan, D., Xiang, G., Chai, X., Qing, J., Shang, H., Zou, B., et al. (2017). Screening of deafness-causing DNA variants that are common in patients of European ancestry using a microarraybased approach. PLoS One 12:e169219. doi: 10.1371/journal.pone.0 169219

Yang, S. M., Chen, W., Guo, W. W., Jia, S., Sun, J. H., Liu, H. Z., et al. (2012). Regeneration of stereocilia of hair cells by forced Atoh1 expression in the adult mamma lian cochlea. PLoS One 7:e46355. doi: 10.1371/journal.pone.0046355

Yu, Y., Weber, T., Yamashita, T., Liu, Z., Valentine, M. B., Cox, B. C., et al. (2010). In vivo proliferation of postmitotic cochlear supporting cells by acute ablation of the retinoblastoma protein in neonatal mice. J. Neurosci. 30, 5927-5936. doi: 10.1523/jneurosci.5989-09.2010

Żak, M., Klis, S. F., and Grolman, W. (2015). The Wnt and Notch signalling pathways in the developing cochlea: formation of hair cells and induction 
of regenerative potential. Int. J. Dev. Neurosci. 47, 247-258. doi: 10.1016/j. ijdevneu.2015.09.008

Zhai, S. Q., Guo, W., Hu, Y. Y., Yu, N., Chen, Q., Wang, J. Z., et al. (2011). Protective effects of brain-derived neurotrophic factor on the noise-damaged cochlear spiral ganglion. J. Laryngol. Otol. 125, 449-454. doi: 10.1017/s0022215110002112

Zielke, N., and Edgar, B. A. (2015). FUCCI sensors: powerful new tools for analysis of cell proliferation. Wiley Interdiscip. Rev. Dev. Biol. 4, 469-487. doi: 10.1002/wdev.189

Zou, B., Mittal, R., Grati, M., Lu, Z., Shu, Y., Tao, Y., et al. (2015). The application of genome editing in studying hearing loss. Hear. Res. 327, 102-108. doi: 10.1016/j.heares.2015.04.016

Zuris, J. A., Thompson, D. B., Shu, Y., Guilinger, J. P., Bessen, J. L., Hu, J. H., et al. (2015). Cationic lipid-mediated delivery of proteins enables efficient protein-based genome editing in vitro and in vivo. Nat. Biotechnol. 33, 73-80. doi: $10.1038 /$ nbt.3081

Conflict of Interest Statement: The authors declare that the research was conducted in the absence of any commercial or financial relationships that could be construed as a potential conflict of interest.

Copyright (C) 2017 Mittal, Nguyen, Patel, Debs, Mittal, Yan, Eshraghi, Van De Water and Liu. This is an open-access article distributed under the terms of the Creative Commons Attribution License (CC BY). The use, distribution or reproduction in other forums is permitted, provided the original author(s) or licensor are credited and that the original publication in this journal is cited, in accordance with accepted academic practice. No use, distribution or reproduction is permitted which does not comply with these terms. 